\title{
Simulación Y APARIENCIA EN EL ÁMBITO LABORAL: LA ESPECIAL SITUACIÓN DEL SUJETO CONTRATANTE
}

[Simulation and Appearance in the Workplace: the Special Situation of the Contracting Party]

\author{
Pedro Irureta Uriarte* \\ Universidad Alberto Hurtado, Santiago de Chile
}

\begin{abstract}
RESUMEN
La simulación y apariencia jurídica han adquirido en el ámbito laboral una profusa acogida en la resolución de cuestiones vinculadas a la identificación del empleador y a la naturaleza jurídica del contrato. Aun cuando se trata de figuras rigurosamente distintas, y más propias del Derecho civil, desde la perspectiva laboral han sido tratadas de manera uniforme, en el entendido que mediante ellas se busca asegurar el cumplimiento de normas imperativas. Estas figuras han sido especialmente aplicadas para resolver los problemas de identificación de los
\end{abstract}

\begin{abstract}
Legal simulation and appearance have been widely accepted when deciding on issues related to the identification of the employer and to the legal nature of the contract in the workplace. Even though these are rigorously different concepts, and more specifically pertaining to the Civil Law, from the labor stand point they have been treated in a uniform manner, on the understanding that the fulfillment of mandatory rules is sought through them. These legal concepts have been specially applied to solve problems such as identification of the parties to the contract,
\end{abstract}

ReCibido el 29 de abril y aCEPTADo el 14 de junio de 2013

* Licenciado en Derecho por la Pontificia Universidad Católica de Chile y doctor en Derecho por la Universidad Complutense de Madrid. Profesor titular de Derecho del trabajo de la Universidad Alberto Hurtado. Correo electrónico: piruret@uahurtado.cl 
contratantes, pero también han servido para evitar la falsedad, el fraude y el abuso de Derecho.

Palabras Clave

Simulación en Derecho del trabajo Apariencia - Fraude de Derecho. but they have also been used to avoid falsehood, fraud and abuse of Law.

\section{KEYWORDS}

Simulation in Labor Law - Appearance - Evasion.

\section{INTRODUCCIÓN}

Uno de los presupuestos filosóficos de la obligatoriedad atribuida a los actos jurídicos, es la identidad que regularmente se produciría entre la voluntad interna y la voluntad declarada, entre el estatus jurídico que se pregona y el que realmente se ostenta en la práctica ${ }^{1}$. Por ello, la vinculación entre cualquier acreedor y deudor tiene como principal efecto el desarrollo regular de lo pactado, debido a que no existe contradicción entre apariencia y realidad, entre el elemento volitivo y la actuación propiamente tal ${ }^{2}$.

Por excepción, puede suceder que la apariencia no se condiga exactamente con la realidad. Ya sea por una actitud deliberada (simulación) ${ }^{3}$, por la concurrencia de un vicio en el consentimiento otorgado por las partes contratantes (por lo general, error o dolo), o simplemente por la falta de cumplimiento en alguna de las formalidades propias de todo contrato ${ }^{4}$, nada impide que se cree una situación ficticia que genera una determinada idea o aspecto que no tiene respaldo efectivo con lo que ocurre en la realidad. En ese esquema se sitúa, por ejemplo, una persona que aparece como acreedor de un determinado crédito del cual no es titular, encarnándose ante terceros o ante las partes contratantes revestido de una apariencia tal que induce al deudor de buena fe a creer, legítimamente, que dicha persona es el verdadero sujeto con el cual se estipuló el acuerdo.

Esta última posibilidad da origen a la denominada a p a r i e $\mathrm{n}$ c i a j u r í d i c a, en cuya virtud una persona pasa a ocupar la posición jurídica de otra, aparentando una condición que en la realidad no ostenta. Dicha divergencia

${ }^{1}$ Véase, por todos: Castán Tobeñas, José, Derecho civil español, común y foral (reimpresión de la 14a edición, Madrid, Instituto Editorial Reus, 1987), I,2, pp. 759 ss.

${ }^{2}$ Albaladejo, Manuel, Derecho Civil (11 $11^{a}$ edición, Barcelona, José María Bosch Editor, 1991), I,2, p. 225.

${ }^{3}$ Albaladejo, Manuel, cit. (n. 2), I,2, p. 226.

${ }^{4}$ Pla Rodríguez, Américo, Los principios del Derecho del trabajo (2a edición, Buenos Aires, Depalma, 1990), pp. 256-257. 
puede tener su origen en un hecho externo a las partes o, lisa y llanamente, en razón de un acuerdo específico en tal sentido, ya que, en este último caso, las personas involucradas en un acto simulador desean mantener en reserva la verdadera naturaleza del acto, o de los sujetos que lo han llevado a cabo.

La simulación, como señala Ferrara, no es realidad, sino ficción de realidad ${ }^{5}$, haciendo aparecer hacia el exterior lo que no es, o mostrando una cosa que realmente no existe ${ }^{6}$. Por tanto, la simulación termina generando una contradicción entre apariencia y realidad ${ }^{7}$, debido a que las partes deciden mantener en secreto el verdadero acto que se está celebrando ${ }^{8}$.

Dicha reserva, en principio, no tiene por qué ser considerada ilegítima9, toda vez que, de conformidad con el principio de libertad de forma, las partes pueden ejecutar cualquier acto jurídico que deseen, siempre y cuando se ajuste a las reglas generales que establece el ordenamiento legal. Si bien la simulación, por lo general, se celebra con el claro objeto de provocar un e $\mathrm{n} g$ a ñ o e $s$ p e c í i i c a los terceros que se relacionan con alguno de los contratantes, de ahí no tiene por qué concluirse a $\mathrm{p}$ r i o r i una intención fraudulenta ${ }^{10}$.

Lo anterior no supone, con todo, que el acto simulador no pueda derivar en una figura legalmente indebida o fraudulenta. Como se sabe, el efecto ilícito de un hecho jurídico no tiene por qué asimilarse, sin más, a una situación dolosa ${ }^{11}$.

${ }^{5}$ Véase: Ferrara, Francisco, La simulación de los negocios jurídicos (reimpresión, traducción castellana de Rafael Atard y Juan A. De la Puente, Madrid, Editorial Revista de Derecho Privado, 1960), p. 42.

${ }^{6}$ Véase: Herrero Nieto, Bernardino, La simulación y el fraude a la ley en el Derecho del Trabajo (Barcelona, Bosch, 1958), p. 14.

${ }^{7}$ Véase: FADEL RAAD, Nabil, L'abus de la personnalité morale en Droit privé (Paris, Librairie Générale de Droit et de Jurisprudence, 1991), pp. 19 ss.

${ }^{8}$ Véase por todos: Díez DuARTe, Raúl, La simulación de contrato en el Código civil chileno (2a edición, Santiago, Fallos del Mes, 1982), pp. 59 ss.

${ }^{9}$ Véase: García VAlverde, María, Los elementos esenciales del contrato de trabajo: visión jurisprudencial, en Documentación Laboral, 45 (1995), I, p. 110.

${ }^{10}$ Véanse entre otros: Batlle Vazeuez, Manuel, Artículo 6 ${ }^{\circ}$, ahora, en AlbaLADEjo, Manuel (director), Comentarios al Código Civily Compilaciones Forales (Madrid, 1978), I, p. 114; Díez-Picazo, Luis - Gullon, Antonio, Sistema de Derecho Civil (6a edición, Madrid, Tecnos, 1992), II, p. 81; Fernández GianotTi, Enrique, Fraude de derechos laborales, en Relaciones Laborales, 1 (1991), pp. 1202-1203; GALIANa Moreno, Jesús María, El fraude de ley en las relaciones de trabajo: un análisis jurisprudencial, ahora en Montoya Melgar, Alfredo - Martin Valverde, Antonio - Rodríguez-SAÑudo GutiéRREZ, Fermín (coordinadores), Cuestiones actuales de Derecho del trabajo, Homenaje al profesor Manuel Alonso Olea (Madrid, Publicaciones Ministerio del Trabajo y Seguridad Social, 1990), pp. 441 y 446; e Iruzubieta FERnÁndez, Rafael, El abuso del Derecho y el fraude de ley en el Derecho del Trabajo (Madrid, Colex, 1989), p. 221.

${ }^{11}$ Véase: Castán Tobeñas, José, cit. (n. 1), I,1, p. 597. 
Lo cierto es que el criterio voluntarista o subjetivo ha cedido paso a la convicción de que igual se produce un abuso de Derecho o un fraude si el resultado de la acción termina siendo dañino o contrario a los preceptos imperativos del ordenamiento jurídico. Además, como se ha encargado de señalar la doctrina, en la mayor parte de los supuestos de fraude -sobre todo en el ámbito laboralqueda en evidencia una voluntad maliciosa que se ampara en el subterfugio o aparato engañoso utilizado, generando una consecuencia antijurídica ${ }^{12}$. Y es justamente en esta última hipótesis donde el problema de la apariencia y la simulación adquieren ribetes especiales, ya que el hecho de que concurra una intención o resultado fraudulento no puede obviarse por el simple expediente de que se ejercitaba una libertad contractual ${ }^{13}$.

Las teorías sobre la apariencia y la simulación constituyen, sin lugar a dudas, una materia íntimamente vinculada al Derecho civil $^{14}$. Es dicha parcela jurídica la que no sólo ha regulado estas figuras, sino que además es la que mayores contribuciones doctrinarias ha efectuado sobre la materia. En el Derecho del Trabajo, por el contrario, si bien es cierto que los problemas de simulación adquieren señales muy características ${ }^{15}$, la verdad es que los aportes que se efectúan al respecto han estado tradicionalmente relegados a una fructífera elaboración jurisprudencial, sin que se haya logrado alcanzar, hasta ahora, el mismo correlato en el ámbito normativo o doctrinario. Lo que ocurre es que en materia de fraude y simulación el ordenamiento laboral no constituye un "recinto cerrado a cal y canto", ni menos autosuficiente ${ }^{16}$.

En efecto, en el ordenamiento laboral ha existido una sistemática conducta de la jurisprudencia que desde temprana época -ya sea por aplicación de las reglas generales del Código del Trabajo, o como una forma de hacer privilegiar

${ }^{12}$ Véase: Galiana Moreno, Jesús María, cit. (n. 10), pp. 446-447. También, Borrajo Dacruz, Efrén, El abuso de derecho en el contrato de trabajo, en Revista de Derecho del Trabajo, 1 (1954) 1, p. 2; Molero Manglano, Carlos, La supletoriedad del Derecho común en el Derecho del trabajo (Madrid, Instituto de Estudios Políticos, 1975), p. 183; y Rodríguez Ramos, María José, La cesión ilegal de trabajadores tras la reforma de 1994 (Madrid, Tecnos, 1995), p. 28.

${ }^{13}$ Véase: Sala Franco, Tomás - López Mora, Federico, Contrato de trabajo, ahora en Borrajo DaCruz, Efrén, Comentarios a las leyes laborales. El Estatuto de los Trabajadores (Editorial de Derecho Reunidas, Madrid, 1985), I, pp. 4-5.

${ }^{14}$ Véanse, entre otros: García PiQueras, Manuel, La simulación en el contrato de trabajo, en Actualidad Laboral, 21 (1990), p. 239; y GARCía Viña, Jordi, El despido nulo por abuso de derecho y fraude de ley: análisis jurisprudencial, en Actualidad Laboral, 45 (1993), p. 809.

${ }^{15}$ Véase: García Piqueras, Manuel, cit. (n. 14), p. 239.

${ }^{16}$ Véase: CASAS BAAMONDE, María Emilia, Irregularidad formal, fraude de ley y nulidad del despido disciplinario, en Relaciones Laborales, 24 (1994), p. 88. También IrUzubieta Fernández, Rafael, cit. (n. 10), p. 309. 
la equidad- han venido sancionando una serie de figuras fraudulentas. La mayor parte de ellas se encuentran vinculadas a la determinación del empleador responsable, la simulación de contratos civiles o mercantiles, la celebración de contratos temporales, así como a todas aquellas materias relacionadas con despidos, siempre y cuando se produzca de este modo un resultado contrario o prohibido por el ordenamiento jurídico-laboral. Con ello se ha querido subrayar una aplicación legítima de la ley laboral, dejando de lado los subterfugios y apariencias que en muchas oportunidades derivan en actos de naturaleza fraudulenta ${ }^{17}$.

En el Derecho chileno, el Código del Trabajo ha establecido normas específicas destinadas a evitar el fraude en determinadas figuras de orden laboral pero colocando el énfasis en la determinación del empleador y en la naturaleza del vínculo contractual. Para el primer caso, el artículo $4^{\circ}$, inciso primero, del Código establece una presunción de derecho en la identidad del empleador declarando que representa a éste, y que en tal carácter lo obliga con los trabajadores, "el gerente, el administrador, el capitán del barco y, en general, la persona que ejerce habitualmente funciones de dirección o administración por cuenta o representación de una persona natural o jurídica". Se trata de una norma cuyo objeto es sustentar la teoría de la validez y suficiencia del representante legal sólo aparente, visible y más a mano a los ojos del trabajador, sin que se le pueda exigir a éste un examen más rígido y técnico de la situación jurídica pertinente ${ }^{18}$. Una orientación similar puede encontrarse en el artículo 507 CT., el cual sanciona al empleador que simule la contratación de trabajadores a través de terceros, y al que utilice cualquier subterfugio, ocultando, disfrazando o alterando su individualización o patrimonio y que tenga como resultado eludir el cumplimiento de las obligaciones laborales y previsionales que establece la ley o la convención. Esta norma constituye un típico caso de fraude de ley ${ }^{19}$, en que se sanciona el resultado conseguido por el agente provocador (más allá de la intencionalidad que éste tenía $)^{20}$. Por último, no cabe duda que la fuerza expansiva del artículo

${ }^{17}$ Véase en el plano doctrinario, y entre otros: López López, Julio, La contratación temporal y el fraude de ley, en Relaciones Laborales, 2 (1990), pp. 339 ss.; y OJEDA AviLÉs, Antonio, Los despidos radicalmente nulos por fraude de ley, en Relaciones Laborales, 24 (1987), pp. 345 ss.

${ }^{18}$ Véase la sentencia de la Corte de Apelaciones Presidente Aguirre Cerda, de 14 de marzo de 1986, en Revista de Derecho y Jurisprudencia, 83 (1986), sección 3a , p. 65; y sentencia de la Corte de Apelaciones de Concepción, de 9 de junio de 1994, en Gaceta Jurídica, 167 (1994), p. 90.

${ }^{19}$ Véanse, por todos: Lizama Portal, Luis, Derecho del trabajo (Santiago, LexisNexis, 2003), p. 50; y Ugarte Cataldo, José Luis, El nuevo Derecho del trabajo (Santiago, Editorial Universitaria, 2004), p. 104.

${ }^{20}$ Una orientación similar puede consultarse en los artículos $183-\mathrm{U}$ y 152 bis-G CT. En el plano doctrinal, véase, además: Irureta Uriarte, Pedro, Vigencia del 
$8^{\circ}$, inciso primero, del Código del Trabajo, también es aplicable en esta referencia toda vez que logra hacer primar la realidad por sobre cualquier subterfugio destinado a disimular la existencia de un contrato laboral ${ }^{21}$.

Con todo, y más allá de estas específicas normas, habrá que reconocer que en el Derecho del Trabajo chileno no existe un acabado y uniforme catálogo de preceptos destinados a evitar las figuras de fraude o simulación. En razón de ello, en el presente artículo se plantean criterios que permitan resolver estos problemas de simulación o fraude, con especial referencia a los casos de identificación del sujeto empleador. Para estos efectos, se realiza un análisis de las figuras de la simulación y la apariencia en el ámbito laboral, haciendo hincapié en los criterios de solución de los c as os difíciles que ha entregado tanto la doctrina como la jurisprudencia. No obstante, y más allá de las referencias puntuales que en cada caso correspondan, no son motivo de análisis otras herramientas de solución tales como el principio de la primacía de la realidad o la teoría del levantamiento del velo.

\section{LA SIMULACIÓN EN LA FIGURA DEL SUJETO CONTRATANTE}

Como es sabido, la simulación, al menos en el ámbito del Derecho civil, pero aplicable también al Derecho del Trabajo, admite una doble distinción en simulación absoluta y relativa ${ }^{22}$. La simulación absoluta concurre cuando

principio de la buena fe en el Derecho del trabajo chileno, en Ius et Praxis, 2 (2011), p. 141 , nota 26.

${ }^{21}$ Como ha señalado CaAmaño Rojo, Eduardo, Análisis crítico sobre la aplicación de la doctrina de los actos propios en materia laboral, en Revista de Derecho de la Pontificia Universidad Católica de Valparaíso, 32 ( ${ }^{\mathrm{er}}$ semestre de 2009), p. 269, esta "norma que consagra la presunción de laboralidad es un presupuesto indispensable para asegurar la eficacia de la legislación laboral y, al mismo tiempo, es una consagración clara del principio de primacía de la realidad a través del cual se busca evitar simulaciones, o encubrimientos formales de la naturaleza del contrato". Véanse, asimismo, y por todas: la sentencia de la Corte de Apelaciones de Santiago, de 30 de marzo de 1987, en Gaceta Jurídica, 81 (1987), p. 87: "Que entre los principios imperantes en materia de derecho del trabajo, y que sirven de inspiración al derecho en esta rama, se encuentra el de primacia de la realidad que para el tratadista Américo Plá Rodriguez 'significa que en caso de discordancia entre lo que ocurre en la práctica y lo que surge de documentos o acuerdos, debe darse preferencia a lo primero, es decir, a lo que sucede en el terreno de los hechos"'; y la sentencia de la Corte Suprema, de 30 de marzo de 2004, en Revista de Derecho y Jurisprudencia, 101 (2004), sección $3^{a}$, pp. 25 y 27: "5: Que, en consecuencia, no es dable admitir que se haya incurrido en el error de derecho de desconocer el contrato de trabajo acompañado al proceso, el que consigna la existencia de relación laboral sólo entre la actora y Antonio Arbea e Hijo, desde que, como se dijo, la Sociedad Panificadora Limitada constituye un subterfugio para eludir el cumplimiento de las obligaciones legales".

${ }^{22}$ Véase, por todos: Díez Duarte, Raúl, cit. (n. 8), pp. 108 ss. En el plano juris- 
se aparenta la celebración de un contrato determinado, aun cuando en la realidad no existe ninguna intención de celebrarlo, generándose una exclusiva apariencia del acto $^{23}$. Ese sería el caso, por ejemplo, en que dos personas fingen la suscripción de un contrato laboral -en la práctica inexistente- a objeto de obtener determinados beneficios previsionales en función de los períodos de ocupación. Igual tipo de simulación concurriría en el supuesto de que ambas partes consientan en celebrar un determinado acto con el objeto fundamental de obtener ciertas ventajas transaccionales, sobre todo en el ámbito indemnizatorio $^{24}$.

La simulación absoluta deja al descubierto, por tanto, un acto jurídico sin causa o con causa falsa, que no tiene nada de real ${ }^{25}$, y cuyas consecuencias se pueden sintetizar en la siguiente figura: la nulidad del negocio jurídico simulado de conformidad con los artículos 1467 y 1682 CC. En ese contexto, la celebración de un contrato de trabajo aparente supondrá dejar sin efecto la apariencia o falsedad, debiendo declararse nulo el contrato laboral. Pero no sólo eso, sino que además, la declaración judicial de la simulación traerá como consecuencia la constatación de una supuesta infracción administrativa, como podría ser la connivencia para obtener prestaciones indebidas. Por ello, la simulación absoluta no sólo genera la nulidad del acto sino que además, y eventualmente, la asunción de responsabilidades de carácter administrativo ${ }^{26}$.

En la simulación relativa, por el contrario, lo que existe es un disimulo del contrato real, sustituyéndolo ficticiamente por un contrato distinto ${ }^{27}$. En este caso, las partes emplean, intencionalmente, el acto o negocio simulado como pantalla, "puesta en escena" o disfraz para ocultar, ante los ojos de terceros, el acto real y verdadero que se ejecuta en la práctica ${ }^{28}$. Por tanto, en la simulación relativa no es que falte voluntad negocial; ella existe, pero se presenta de modo

prudencial, puede verse la sentencia de la Corte de Apelaciones de Santiago de 27 de mayo de 2003, en Revista de Derecho y Jurisprudencia, 100 (2003), sección 2a , p. 72.

${ }^{23}$ Véanse, por todos: CABAnellas, Guillermo, Tratado de Derecho laboral (3a edición, Buenos Aires, Heliasta, 1987), II,1, p. 346; CASTÁn Tobeñas, José, cit. (n. 1), I,2, p. 763; Galiana Moreno, Jesús, cit. (n. 10), p. 442; Herrero Nieto, Bernardino, cit. (n. 6), p. 91; y Pla Rodríguez, Américo, Los principios, cit. (n. 4), p. 256.

${ }^{24}$ Véase: OJeda Avilés, Antonio, Los despidos radicalmente nulos, cit. (n. 17), p. 356. Rey Guanter, Salvador, Potestad sancionadora de la administración y jurisdicción penal en el orden social (Madrid, Centro de Publicaciones Ministerio de Trabajo y Seguridad Social, 1990), p. 305.

${ }^{25}$ Véase: Fernández Gianotti, Enrique, cit. (n. 10), p. 1201.

${ }^{26}$ Artículo 507 CT.

${ }^{27}$ Véase: Ferrara, Francisco, cit. (n. 5), pp. 49 y 205; y Pla Rodríguez, Américo, Los principios, cit. (n. 4), p. 256.

${ }^{28}$ Véase: Herrero Nieto, Bernardino, cit. (n. 6), pp. 92 y 411; e Iruzubieta FERNÁNDEZ, Rafael, cit. (n. 10), pp. 235-236. 
distorsionado, toda vez que la s i m u $\mathrm{l}$ a c i ó n no afecta a la existencia misma del negocio jurídico, sino a su tipo ${ }^{29}$.

Con todo, la simulación relativa también traerá como consecuencia el hecho de que el negocio simulado sea declarado nulo, debiendo prevalecer el c o n t r a t o o c u l t o. Esta hipótesis, de usual ocurrencia por lo demás en el ámbito laboral ${ }^{30}$, se encuentra, por ejemplo, en los servicios prestados bajo la fórmula jurídica de un contrato civil, cuando en verdad lo que existe es una prestación personal e intransferible, dentro del ámbito directivo del empleador ${ }^{31}$; en los supuestos penales de simulación de contrato ${ }^{32}$; en los casos de interposición ficticia; en las distorsiones que se experimentan sobre uno de los elementos singulares del contrato (como es el monto de la retribución o la fecha de entrada en vigencia del acuerdo contractual) ${ }^{33}$; o en los contratos de representación mercantil en que la realidad demuestra que no existe comi$\operatorname{sión}^{34}$. Todo esto pone de manifiesto una apariencia que no se condice con la verdadera intención de las partes ${ }^{35}$.

Hay que tener presente que en estos casos no se trata de un error -por ignorancia o confusión- en la denominación del acto jurídico, ya que si así fuera simplemente habría que aplicar la regla de interpretación en cuya virtud es preciso atenerse a la voluntad real de las partes $^{36}$. Por el contrario, en la simulación relativa lo que existe es la preparación de antemano de una apariencia con un fin engañoso ${ }^{37}$, a fin de distorsionar la apreciación que los terceros tienen desde el exterior del acto.

Sin embargo, estas distorsiones intencionalmente provocadas resultan in-

${ }^{29}$ Véase: Rey Guanter, Salvador, cit. (n. 24), p. 305.

${ }^{30}$ Véanse Alonso Olea, Manuel - Casas BaAmonde, María Emilia, Derecho del trabajo (13 edición, Madrid, Servicio de Publicaciones, Facultad de Derecho Universidad Complutense, 1993), p. 195; LoRENZETTI, Ricardo Luis, El fraude en el Derecho laboral, ahora en AA. VV, Fraudes (Santa Fe, Revista de Derecho Privado y Comunitario, 1993), pp. 283 ss.

${ }^{31}$ Véase: Montoya Melgar, Alfredo, Derecho del trabajo (29a edición, Madrid, Tecnos, 2008), p. 282.

${ }^{32}$ Artículo 471 No 2 CP.

${ }^{33}$ Véanse Herrero Nieto, Bernardino, cit. (n. 6), pp. 92-93; Rodríguez RAmos, María José, cit. (n. 12), pp. 36 y 150.

${ }^{34}$ Véase: Rey Guanter, Salvador, cit. (n. 24), p. 306.

35 Aquí radica una distinción relevante entre el ordenamiento civil y la disciplina laboral. En efecto, para el artículo 1707 CC. las "escrituras privadas hechas por los contratantes para alterar lo pactado en escritura pública, no producirán efecto contra terceros". En el fondo, el artículo 1707 respalda la voluntad declarada (no la real), pero al mismo tiempo establece la inoponiblidad del acto jurídico oculto si éste es perjudicial para los terceros. Sobre el particular, véase: Díez Duarte, Raúl, cit. (n. 8), p. 20.

${ }^{36}$ Montoya Melgar, Alfredo, Derecho, cit. (n. 31), p. 269.

${ }^{37}$ Ferrara, Francisco, cit. (n. 5), p. 209. 
trascendentes de conformidad con lo establecido en los artículos 5, 7 y 8 CT. En este último caso, si el contrato se entiende celebrado entre toda persona que presta un servicio bajo $s$ u b o r i n a c i ón o d e pendencia, entonces habrá que concluir que al ordenamiento jurídico no le interesa el acto que disfraza la existencia jurídica del contrato de trabajo, sino que, por el contrario, hace prevalecer la verdadera intención -expresa o tácita- de los contratantes, confirmando el carácter no formal del acto jurídico-laboral. ${ }^{38}$ Con ello, como señala un autor, "más que negar el juego de la autonomía de la voluntad, de lo que se trata es de potenciar la voluntad real y querida frente a la disimulada". ${ }^{39}$

Lo relevante de todas estas consideraciones lo constituye el hecho de que la simulación, debido al carácter que presenta, constituye sin lugar a dudas una de las alternativas más concretas para burlar los propósitos del legislador, permitiendo un claro contraste entre el significado que un acto o conjunto de actos tiene hacia el exterior -jurídica y objetivamente considerados-, y el que verdaderamente le han atribuido sus autores ${ }^{40}$.

La simulación en el ámbito laboral se podrá traducir en una serie de alternativas de incumplimiento. Puede referirse, por ejemplo, a la naturaleza de un acto, a la ejecución debida de la ley, a la validez de los requisitos formales, o a la comisión de un fraude legal, entre otros varios aspectos. Pero sin lugar a dudas, una de las manifestaciones más elocuentes de simulación laboral guarda relación con la exacta determinación del "s u j e t o e m p le a d o r r e s p o n s a b l e ". De allí que el legislador haya puesto especial énfasis en dilucidar distorsiones en su figura, consagrando preceptos al estilo del artículo $4^{\circ}$ y 507 CT., toda vez que la suerte del vínculo laboral no se encuentra sujeta a las mutaciones jurídicas de la empresa, sino que se atiende a la subsistencia de la actividad empresarial, "desestimando los cambios jurídicos que experimente la persona del empresario y aún la transferencia de la empresa" ${ }^{\text {”11. }}$.

${ }^{38}$ Alonso Olea, Manuel - Casas Baamonde, María Emilia, cit. (n. 30), p. 201 : "no son necesarias declaraciones expresadas a través del lenguaje; específicamente quien 'recibe un servicio' [...] y, por tanto, 'no rehusa una prestación de trabajo hecha en su favor', sigue con ello una conducta inequívoca o tiene un comportamiento concluyente $[\ldots]$ de que el contrato nace".

${ }^{39}$ Luján AlCARAZ, José, La contratación privada de servicios y el contrato de trabajo (Madrid, Centro de Publicaciones Ministerio de Trabajo y Seguridad Social, 1994), p. 272.

${ }^{40}$ Carballo Mena, César Augusto, Comentarios sobre la simulación en el Derecho del trabajo venezolano (su incidencia sobre la libertad sindical), ahora en HERNÁNDEZ Álvarez, Oscar (coordinador), La Reforma laboral en América Latina (Venezuela, Tipografía Horizonte, 1995), p. 200.

${ }^{41}$ Véase la sentencia de la Corte Suprema, de 17 de abril de 1985, en Revista de Derecho y Jurisprudencia, 82 (1985), sección 3a , p. 32; y sentencia de la Corte Suprema, 


\section{Supuestos de simulación.}

Desde una perspectiva amplia, la simulación en la figura del empleador puede obedecer, a lo menos, a cuatro esquemas posibles.

a) Acuerdo simulador que encubre un acto $\mathrm{l}$ a b o r a 1 . Por una parte, la figura simuladora puede tener su origen en un acuerdo entre empleador y trabajador efectuado con el objeto de distorsionar la naturaleza del acto o alguno de sus elementos, aunque sin que exista necesariamente un propósito de fraude ${ }^{42}$. En ese esquema, el sujeto contratante no aparece como e $\mathrm{m} \mathrm{p} \mathrm{l}$ e a $\mathrm{d}$ o $\mathrm{r}$ sino que como un simple acreedor civil o comercial dependiendo del contrato que aparentemente se celebra. Los motivos de esta actuación se pueden encontrar, por ejemplo, en la necesidad de obtener algún beneficio económico, por parte del trabajador, o eludir el cumplimiento de determinadas leyes laborales, por parte del empleador ${ }^{43}$. No obstante, y a pesar de la concurrencia de la voluntad simuladora de ambos contratantes, lo cierto es que la eficacia real de esta hipótesis resulta bastante improbable dentro del ámbito laboral, toda vez que el carácter irrenunciable de las normas del Código del Trabajo hace casi imposible prefigurar una situación engañosa, pero lícita ${ }^{44}$, en que se encubran o renuncien determinados derechos. En la legislación del trabajo las cosas so n lo que so ${ }^{45}$, y si se configura una prestación de servicios revestida de los elementos señalados en el artículo 7 CT., entonces necesariamente existirá un trabajador y un empleador. Por tanto, si llegase a concurrir un acuerdo simulador con intervención del trabajador, dicha conducta estaría viciada de nulidad de conformidad con el artículo 5 CT. ${ }^{46}$.

de 20 de marzo de 2004, en Revista de Derecho y Jurisprudencia, 101 (2004), sección $3^{\mathrm{a}}$, p. 25.

${ }^{42}$ Castán Tobeñas, José, cit. (n. 1), I,2, p. 763; y García Piqueras, Manuel, cit. (n. 14), p. 239.

${ }^{43}$ Cabanellas, Guillermo, cit. (n. 23), p. 347; y Carballo Mena, César, cit. (n. 40), pp. 206-207. Con todo, hay que tener presente que la aparente coincidencia de voluntad entre trabajador y empleador puede tener su origen en un vicio del consentimiento, o en una voluntad mediatizada, inducida hacia la celebración del contrato simulado (así Iruzubieta Fernández, Rafael, cit. [n. 10], p. 223).

${ }^{44}$ OJeda Avilés, Antonio, La renuncia de derechos del trabajador (Madrid, Instituto de Estudios Políticos, 1971), pp. 241-242.

${ }^{45}$ Véase, por todos: Iruzubieta Fernández, Rafael, cit. (n. 10), p. 222: “aunque, de buena fe y sin concierto previo de voluntades, se hubiera suscrito un contrato de naturaleza no laboral y sus prestaciones y características de fondo se correspondieran con una relación jurídica de trabajo, prevalecería ésta sobre aquél; y ello conforme [...] (al) principio de que 'los contratos son lo que realmente son, y no lo que las partes dicen que son"”.

${ }^{46}$ Véanse: Palomeque López, Manuel Carlos - Álvarez de la Rosa, Manuel, Derecho del trabajo (3a edición, Madrid, Centro de Estudios Ramón Areces, 1995), p. 710; Palomeque-López, Manuel Carlo, Validez del contrato, en Borrajo Dacruz, 
Distinta sería la situación, en todo caso, si se tratara de acuerdos simulados del ámbito penal, ya que en dicha hipótesis el conocimiento del trabajador supondría excluir la aplicación del delito a que se refiere el artículo $471 \mathrm{~N}^{\circ} 2 \mathrm{CP}$.

Excepcionalmente, aunque en una perspectiva no estrictamente laboral, es posible pensar en casos de simulación de derechos siempre y cuando ellos se refieran a situaciones extralaborales como podrían ser los supuestos de compraventa o donaciones simuladas entre empleador y trabajador. Pero allí ya no se estaría hablando de una simulación en la figura empleadora, sino que de otros elementos que escapan a la exacta determinación de los sujetos contratantes. Por ello, la verdad es que toda actuación jurídica destinada a dejar sin efecto determinados derechos laborales irrenunciables -aun cuando no se haya efectuado con una intencionalidad ilegítima-, tenderá a ser considerada fraudulenta en razón de sus resultados ${ }^{47}$.

b) Actos válidos que generan un resultado $\mathrm{fr}$ a u d u l e $\mathrm{n} t \mathrm{o}$. Una segunda posibilidad, muy unida a la anterior, es que las partes realicen un contrato disimulado formalmente válido, pero de carácter ilícito, que se opone a las normas substantivas del ordenamiento laboral ${ }^{48}$. En esa hipótesis se encontrarían, por ejemplo, la celebración de un contrato de prestación de servicios con un menor de dieciséis años; o cuando el trabajador se ve obligado a aceptar condiciones contractuales que no se compadecen con la realidad $^{49}$, ya sea en cuestiones relativas a la remuneración, antigüedad, o a otros elementos propios del negocio jurídico-laboral ${ }^{50}$, que terminan distorsionando la figura del contratante.

Hay que tener presente, que en estos casos no existe error o un falso concepto del acto específico que se celebra. Muy por el contrario, las partes, ya sea forzadas por la actuación de una de ellas o por un acuerdo bilateral, llevan a cabo una simulación fraudulenta destinada a quebrantar normas imperativas del ordenamiento jurídico. Y eso, sencillamente, constituye un fraude de ley ${ }^{51}$. En

Efrén, Comentarios a las leyes laborales. El Estatuto de los Trabajadores (Editorial de Derecho Reunidas, Madrid, 1985), III, pp. 38-39.

${ }^{47}$ Iruzubieta Fernández, Rafael, cit. (n. 10), pp. 217-219, 228 y 280.

${ }^{48}$ Véase, aunque en relación con el Derecho civil, pero aplicable al ámbito laboral: Batlle Vázquez, Manuel, cit. (n. 10), p. 114; y Castán Tobeñas, José, cit. (n. 1), I, 2, p. 763 .

49 Véanse: Carballo Mena, César, cit. (n. 40), p. 205; y Fernández GianotTI, Enrique, cit. (n. 10), p. 1205; Cabanellas, Guillermo, cit. (n. 23), p. 347: “[...] cuando acepta el trabajador figurar en calidad distinta a la real: por ejemplo, de viajante libre, siendo en realidad subordinado o estando en relación de dependencia”.

${ }^{50}$ García Pilueras, Manuel, cit. (n. 14), p. 248.

${ }^{51}$ Véanse: Castán Tobeñas, José, cit. (n. 1), 1, I, p. 596; Carballo Mena, César, cit. (n. 40), p. 202. 
este caso, por tanto, no es que haya duda sobre la identidad del sujeto, sino que existen elementos que afectan la validez de la caracterización empleadora.

c) El sujeto aparente como agente simulador. Un tercer caso, de bastante ocurrencia en el ámbito del Derecho del Trabajo, es el relativo a la celebración de un contrato laboral entre un trabajador y un empleador aparente, que simula tener la titularidad de la actividad empresarial ${ }^{52}$. Dicho supuesto presupone una actitud simulada o encubierta del verdadero acreedor de trabajo, y generalmente se verifica, entre otras posibilidades, mediante la intervención de un testaferro incapaz de solventar las deudas derivadas de la prestación de servicios (o incluso, mediante la creación de entes artificiales que pretenden disimular la responsabilidad del titular $)^{53}$.

El ficticio empleador, en estos casos, resulta ser un simple intermediario, ya que el verdadero receptor de los servicios prestados por el dependiente es un tercero que no interviene formalmente en la celebración del acto, encontrándose oculto ante terceros. La creación de una estructura empresarial artificial le permite justamente eludir la aplicación de las normas laborales ${ }^{54}$. El trabajador, por su parte, no sólo ignora la situación real, sino que además, muchas veces, se le disfraza con una apariencia determinada, siendo muy difícil establecer la exacta identidad del empleador responsable. En este supuesto se encontrarían, entre otros, las seudo subcontrataciones, la cesión ilícita de trabajadores, o las figuras vinculadas a lo que doctrinariamente se conoce como el e m p r e s a r i o o c u l t o. En todos estos casos, la realidad deja al descubierto una interposición fraudulenta que deriva en un incumplimiento de las obligaciones laborales ${ }^{55}$.

d) La simulación en perjuicio de terceros aje-

52 Por todos: Cabanellas, Guillermo, Tratado, cit. (n. 23), p. 347.

${ }^{53}$ Véase el caso resuelto en esta línea por la sentencia de la Corte de Apelaciones de Santiago, de 7 de noviembre de 1990, en Gaceta Jurídica, 125 (1990), p. 90: "Que aun cuando una empresa cambie de nombre o razón social, si sigue dedicada al mismo rubro, funcionando en el mismo local y con el mismo representante social es obvio que para los trabajadores ella continúa siendo la misma [...]". En esa misma línea están la sentencia de la Corte Suprema, de 13 de abril de 1987, en Gaceta Jurídica, 82 (1987), p. 97; la sentencia de la Corte de Apelaciones de Santiago, de 11 de abril de 1985, en Gaceta Jurídica, 58 (1985), p. 165; y la sentencia de la Corte Suprema, de 20 de marzo de 2004, en Revista de Derecho y Jurisprudencia, 101 (2004), sección 3a , p. 25.

${ }^{54}$ Rodríguez Ramos, María José, cit. (n. 12), p. 28.

${ }^{55}$ Martin VAlverde, Antonio, Interposición y mediación en el contrato de trabajo, en Revista de Politica Social, 91 (1971), p. 39. Véanse también: Lizama Portal, Luis - Ugarte Cataldo, José Luis, Subcontratación y suministro de trabajadores (2a edición, Santiago, LexisNexis, 2007), pp. 5 ss.; y Rojas MiÑo, Irene, Subcontratación laboral, suministro de trabajo y cesión ilegal de trabajadores (Santiago, AbedeloPerrot/ Thomson Reuters, 2011), pp. 171 ss. 
n o s a l vín c u l o la b o r a l. Laúltima alternativa que se puede dar en la práctica laboral es que exista una simulación del contrato de trabajo en fraude de los acreedores de uno de los contratantes ${ }^{56}$. Ya sea el empleador, o incluso el propio trabajador, desean expresar hacia el exterior una determinada situación patrimonial a objeto de evitar ejecuciones o cumplimientos forzados de sus deudas. No es que se quieran burlar los derechos del trabajador, o el cumplimiento de las leyes laborales, simplemente se desea proyectar una imagen determinada hacia terceros extraños al contrato de trabajo. En ese estadio se encontraría, por ejemplo, un trabajador condenado al pago de pensiones alimenticias, el cual, para sustraerse de esta ejecución, simula un monto de remuneración inferior al efectivamente obtenido, o la encubre bajo otro título jurídico como podría ser la compraventa o los honorarios profesionales ${ }^{57}$.

Sin embargo, la fuerza de la normativa laboral, así como de otros preceptos de evidente naturaleza pública, hacen muy difícil la generación de efectos válidos en este tipo de actuaciones. Al existir un fraude en relación con terceros, la ilicitud igual se produce, aun cuando se de fiel cumplimiento a los derechos y obligaciones que nacen del vínculo laboral. La presunción de existencia del contrato de trabajo no sólo se produce en lo que respecta al fuero interno de los contratantes, sino que ella también debe ser capaz de desplegar todos sus efectos a despecho de las convenciones privadas de las partes ${ }^{58}$. Por lo demás, el ordenamiento también busca proteger el patrimonio como garantía común de los acreedores, razón por la cual no resulta admisible este tipo de prácticas.

Como se puede apreciar, en todos los casos que se han mencionado, la simulación se encuentra orientada o guiada por la idea de eludir una determinada obligación contractual ${ }^{59}$, o por el propósito de salvar aquellas limitaciones impuestas por la ley, por los Tribunales o por los órganos administrativos ${ }^{60}$, y en cuya virtud los sujetos de la relación jurídica de trabajo se encuentran impedidos de realizar determinado tipo de actos, afectando la licitud o validez de los mismos. De igual forma, la simulación se realiza con el evidente propósito de acogerse a un régimen de protección o privilegio que la legislación laboral garantiza a cada una de las partes de la relación de trabajo. En fin, lo que subyace, en definitiva, es la clara intención de sustraerse al cumplimiento de una norma

${ }^{56}$ Galiana Moreno, Jesús María, cit. (n. 10), p. 441; y Herrero Nieto, Bernardino, cit. (n. 6), pp. 359-360.

${ }^{57}$ Cabanellas, Guillermo, cit. (n. 23), II,1, p. 347. Véase también: IRUzubieta FERNÁNDEZ, Rafael, cit. (n. 10), p. 216.

${ }^{58}$ Iruzubieta Fernández, Rafael, cit. (n. 10), p. 212.

${ }^{59}$ García Pilueras, Manuel, cit. (n. 14), p. 244.

${ }^{60}$ Carballo Mena, César, cit. (n. 40), pp. 201 y 203. 
de carácter imperativo consagrada en el ordenamiento jurídico ${ }^{61}$, mediante una divergencia consciente entre voluntad declarada y voluntad real.

\section{La respuesta del ordenamiento jurídico.}

Enfrentado a cada una de estas situaciones fraudulentas, el ordenamiento laboral no ha podido permanecer ajeno. A fin de cuentas, lo que le interesa al Derecho del Trabajo, es que el conjunto de normas configuradoras del entramado de relaciones laborales se lleve a cabo de forma adecuada y regular. Por ello, y aun cuando la simulación ilícita, el fraude o el abuso sean figuras rigurosamente distintas, lo cierto es que uniformemente ellas han sido utilizadas como posibles alternativas de elusión de obligaciones imperativas ${ }^{62}$, cuestión que ha obligado a arbitrar medidas adecuadas tendientes a proteger ese entramado normativo sobre el cual se edifican las relaciones de trabajo ${ }^{63}$. Eso permite amparar los derechos de las partes por encima de la apariencia jurídica o de las meras actuaciones simuladas, evitando la desviación del ordenamiento jurídico ${ }^{64}$.

Los mecanismos impetrados para esta protección son diversos y, más aun, específicos a supuestos determinados. En algunos casos el ordenamiento jurídico tenderá a tomar en cuenta la apariencia y a revestirla de consecuencias jurídicas a objeto de proteger a quien de buena fe confió en dicha externalidad. En otros, por el contrario, el Derecho optará por desconocer la situación aparente, prescindiendo de las formalidades ${ }^{65}$, precisamente para que la realidad de los hechos o sus elementos substantivos permitan amparar adecuadamente los intereses jurídico-laborales de los sujetos involucrados en un contrato de trabajo. $\mathrm{O}$ en otros supuestos, por último, el ordenamiento se limitará a establecer un efecto o una sanción para los casos de incumplimiento.

De este modo, en el ámbito del Derecho del Trabajo, apariencia jurídica, confianza creada y primacía de la realidad son enfoques diversos pero que apuntan a una misma finalidad, cual es la de evitar la falsedad, el fraude y el abuso

${ }^{61}$ Fernández Gianotti, Enrique, cit. (n. 10), p. 1204.

${ }^{62}$ Véanse, en esta línea: García ViÑas, Jordi, cit. (n. 14), pp. 810 a 812; López López, Julio, cit. (n. 17), p. 339; y Rodríguez Ramos, María José, cit. (n. 12), p. 151; también: Iruzubieta Fernández, Rafael, cit. (n. 10), p. 202: "se confunden en el vigente Derecho del Trabajo dos figuras (fraude y abuso) que, sin perjuicio de sus puntos de contacto, están bastante deslindadas en el Derecho civil".

${ }^{63}$ Fernández Gianotti, Enrique, cit. (n. 10), p. 1.199; y Molina NavarreTE, Cristóbal, Persona jurídica y disciplina de los grupos de sociedades (Zaragoza, Publicaciones del Real Colegio de España, Bolonia, 1995), p. 54.

${ }^{64}$ Iruzubieta FernándeZ, Rafael, cit., (n. 10) p. 90.

${ }^{65}$ Ángel YagüEz, Ricardo de, Apariencia jurídica, posesión y publicidad inmobiliaria registral (reimpresión, Bilbao, Publicaciones de la Universidad de Deusto, 1982), p. 26; y Menezes Cordeiro, António, Manual de Dereito do trabalho (reimpresión, Coimbra, Livraria Almedina, 1994), p. 557. 
de derecho en lo que respecta al cumplimiento de las facultades y obligaciones que dimanan de un acto jurídico-laboral ${ }^{66}$. Si el propio ordenamiento busca la protección de la buena fe como regla de conducta básica de todos los actos jurídicos, lógico es suponer entonces que se privilegien valores normativos como el amparo de la confianza creada o la preeminencia de la materialidad subyacente.

No es de extrañar, por tanto, que en determinados supuestos el ordenamiento laboral opte por la tutela de la confianza o de la apariencia creada ${ }^{67}$, o en otros por la primacía de la materialidad subyacente, ya que siempre la ley se encontrará motivada por la idea de evitar una actuación falsa o fraudulenta en el goce efectivo de los derechos, privilegiando una adecuada y saludable transparencia. Ante la dialéctica entre forma jurídica y realidad, el ordenamiento optará, en algunos casos, por esta última a objeto de evitar una actuación dañosa para alguna de las partes, aplicando la vieja máxima de que las cosas que se hacen simuladamente se tienen por no hechas ("Quae simulate geruntur, pro infectis habentur"); o en otros casos, deberá amparar la apariencia creada, ya que de otra forma se produciría una burla indebida en los derechos legalmente consagrados. Y lo anterior no podría ser de otro modo, pues la legislación en general jamás deberá entenderse facultada para amparar el abuso ${ }^{68} \mathrm{o}$ el ejercicio antisocial de un derecho, provocando de esta forma un daño a terceros ${ }^{69}$.

A base de las argumentaciones antedichas, hay que tener presente que tanto la jurisprudencia como los diversos cuerpos legales reguladores del ámbito laboral, han utilizado diversos caminos argumentativos para hacer frente al fraude o al abuso de un Derecho, dentro de los cuales destaca por cierto la protección de la apariencia jurídica. También, se han utilizado criterios más vinculados al

${ }^{66}$ Con todo, hay que tener presente que en la figura del fraude no hay apariencia, sino que, por el contrario, se trata de un acto serio y realmente querido por el agente. Por su parte, la simulación, tal como se dijo, no siempre lleva implícita la idea de fraude pues perfectamente una persona podrá realizar un negocio con la idea de "ocultar", pero no de "dañar". Como señala Ferrara, Francisco, cit. (n. 5), p. 81, "la ocultación ni pone ni quita nada al negocio realizado: apartando el velo engañador, queda el negocio en su verdadera esencia, en su realidad desnuda y escueta, y si este negocio resulta en contradicción con una ley imperativa se tendrá un contra legem, no un in fraudem legis agere. La simulación no es medio de eludir la ley, sino de ocultar su violación”.

${ }^{67}$ De Los Mozos, José Luis, El principio de la buena fe (Barcelona, Bosch, 1965), p. 265.

${ }^{68}$ CAPÓn Filas, Rodolfo E., El abuso del Derecho en relación al contrato de trabajo, ahora en AA. VV., Estudios de Derecho individual de trabajo en homenaje al profesor Mario L. Deveali (Buenos Aires, Heliasta, 1979), pp. 763 ss.

${ }^{69}$ Menezes Cordeiro, António, cit. (n. 65), p. 557; y Sagardoy Bengoechea, Juan Antonio, Los principios de aplicación del Derecho del trabajo (2a edición, Madrid, ACARL, 1991), pp. 11 y 12. 
principio de primacía de la realidad, así como a la teoría del levantamiento del velo de la personalidad jurídica, aun cuando habrá que reconocer que la mayor parte de estas figuras se terminan reconduciendo a supuestos de ineficacia jurídica ${ }^{70}$. A todas estas alternativas habría que agregar, por cierto, una serie de preceptos que reflejan determinados principios del Derecho del Trabajo. Por ejemplo, tanto la irrenunciabilidad como el principio protector encuentran un adecuado reflejo en la normativa legal, sirviendo de mecanismo ad-hoc para hacer frente a los actos simuladores o fraudulentos. Con todo, no cabe duda que

${ }^{70}$ Palomeque López, Manuel Carlos, cit. (n. 46), p. 31 . Como se sabe, la ineficacia constituye una sanción; y esa sanción tiene su origen en una disconformidad entre la formalidad externa de un acto y el supuesto prefigurado por el ordenamiento jurídico [cfr., García Viñas, Jordi, cit. (n. 14), p. 809]. Esta disconformidad trae como consecuencia la nulidad; la anulabilidad; y la rescindibilidad. Estas nociones generales son aplicables, por cierto, a la situación del contrato de trabajo. Véanse Molero MANGlano, Carlos, cit. (n. 12), p. 278; y Palomedue López, Manuel Carlos, cit. (n. 46(, pp. 34 y 35 . Si este acto jurídico incurre en alguno de los supuestos que hemos señalado, entonces recaerá sobre dicho acto la sanción de nulidad, sin que se produzcan los efectos que las partes buscaban. Lo anterior no obsta, en todo caso, a que el negocio derive en consecuencias indirectas, como podrían ser el establecimiento de daños y perjuicios, o incluso, que se produzcan los efectos que las partes o una de ellas precisamente quisieron evitar. El Código del Trabajo no contiene preceptos generales relativos a la cuestión de la nulidad, aun cuando existen preceptos específicos que sancionan la nulidad de un aspectos determinado (v. gr., el artículo 183-Q CT. que según el cual será "nula la cláusula del contrato de puesta a disposición de trabajadores de servicios transitorios que prohíba la contratación del trabajador por la usuaria a la finalización de dicho contrato"). En razón de lo anterior, en la mayor parte de los casos de nulidad tendrá que hacerse una referencia obligada a las normas que rigen en el ámbito del Derecho civil. La anulabilidad, por su parte, se da cuando, concurriendo aparentemente todos los elementos exigidos por la ley para la configuración de un acto jurídico, éste adolece de algún vicio que lo invalida con arreglo a Derecho [cfr., CASTÁn TOBEÑas, José, cit. (n. 1), III, p. 766]. En esta hipótesis se encontraría, por ejemplo, el artículo 13 CT. o, también, en los supuestos generales de vicios de la voluntad. En los casos de anulabilidad, el contrato surte efectos normalmente hasta que, mediante la respectiva acción, la sentencia judicial destruye esos efectos. La sentencia, por tanto, no hace más que restablecer las cosas a la situación inmediatamente anterior, borrando todos los efectos del acto [cfr. García Viñas, Jordi, cit. (n. 14), p. 811]. Por último, el ordenamiento legal establece lo que lo que se ha dado en llamar la rescindibilidad del negocio jurídico, en cuya virtud una parte puede reparar el perjuicio económico que le ha causado el contrato. Si bien el negocio es válido, la existencia de un perjuicio habilita a la parte afectada para entablar la respectiva acción de impugnación [cfr. CASTÁn TOBEÑas, José, cit. (n. 1), III, pp. 779 ss.; y Molero Manglano, Carlos, cit. (n. 12), pp. 278-279]. Fuera de estos casos, también cabe destacar la sanción de nulidad, sobre todo en los supuestos de despido en fraude de ley, que elimina totalmente el negocio jurídico envolvente o fraudulento a fin de que tenga aplicación la norma que se intenta esquivar; Véase: OJEDA Avilés, Antonio, Los despidos radicalmente nulos, cit. (n. 17), pp. 362 y 363. 
cada una de estas alternativas ha sido utilizada de acuerdo a las circunstancias concretas, e inspiradas en normas legales de carácter general.

Uno de los rasgos más distintivos de estas teorías radica, sin lugar a dudas, en una cuidada y fructífera elaboración jurisprudencial, que ha obligado a ir resolviendo, caso a caso, las diversas situaciones de ficción laboral. En virtud de esa misma jurisprudencia se ha podido establecer un catálogo de criterios destinados a determinar quién es el e $\mathrm{m}$ p l e a d o r r e a l, y cuál es la exacta naturalezade un vín c u l o c o n t r a c t u a l, superandola a par i e n c i a e m p r e s a ri a ${ }^{71}$, a fin de imputar responsabilidades y proteger al trabajador en su relación con el verdadero empleador.

Un obstáculo, en este contexto, se produce por cierto en la carencia -al menos en el ordenamiento jurídico nacional- de un estructurado y específico cuerpo normativo capaz de resolver situaciones altamente complejas ${ }^{72}$. Muy por el contrario, si bien es cierto que existen algunas referencias específicas relativas al principio de irrenunciabilidad, al de la preeminencia de la realidad o a la sanción del fraude, en la práctica muchas de estas normas han tenido que ser interpretadas y complementadas con otros principios generales del Derecho. En razón de ello, la jurisprudencia laboral -fundamentalmente indiciaria- ha terminado elaborando una innegable o p c i ó $\mathrm{n} v$ a $\mathrm{l}$ o $\mathrm{r}$ a $\mathrm{t}$ i v a que privilegia una noción básica de justicia aplicada a casos en que no existe una solución específica del ordenamiento jurídico.

Las conclusiones anteriores adquieren especial importancia en lo que se refiere al fraude en la figura del sujeto contratante. Por cierto, tal como se ha explicado, la simulación afecta, en la práctica, a diferentes esferas del ámbito laboral; no obstante, y debido también a la falta de una norma precisa al respecto, los problemas de determinación del sujeto empleador han sido de los que han ocupado mayor relieve en el análisis de la jurisprudencia. Ello tiene su explicación, entre otras cosas, en el propio concepto de empleador que, sin ser unívoco, ha experimentado en el Derecho del Trabajo una notable evolución desde aquellos primeros tiempos en que ese e $\mathrm{m}$ p $\mathrm{l}$ e a $\mathrm{d}$ o $\mathrm{r}$ era confundido o asimilado con el dueño o propietario del establecimiento; hasta nuestros días en que la propiedad de un negocio se halla diseminada y en que el poder directivo real se encuentra ejercido por una serie de $\mathrm{m}$ a $\mathrm{n}$ a $\mathrm{g}$ e $\mathrm{r} \mathrm{s}$ cuyas decisiones son luego aprobadas o rechazadas en la asamblea de socios. En la actualidad, por tanto, existe una clara disociación entre propiedad (riesgo) y control directo de la gestión social ${ }^{73}$.

${ }^{71}$ Rodríguez Ramos, María José, cit. (n. 12), pp. 69 y 75.

${ }^{72}$ Véase, por todos: Ugarte Cataldo, José Luis, cit. (n. 19), p. 107.

${ }^{73}$ Sobre esta evolución, a nivel doctrinario, véanse: MARTínEZ Giron, Jesús, El empresario aparente (Madrid, Civitas, 1992), p. 13; Menéndez Menéndez, Aurelio, Auxiliares del empresario, en Revista de Derecho Mercantil, 27 (1959) 72, p. 273. 


\section{LA PROTECCIÓN DE LA APARIENCIA}

La doctrina de la apariencia, aun cuando no constituye un principio general del Derecho, ha sido frecuentemente utilizada por los ordenamientos jurídicos a objeto de hacer prevalecer -en razón de la seguridad del tráfico negociallos actos ejecutados por el titular aparente o ficticio respecto al patrimonio y esfera de actuación del titular efectivo ${ }^{74}$. Dicha seguridad ha llevado a que el ordenamiento legal tienda a proteger a quien, de buena fe, ha confiado en la apariencia, tomando por buenas situaciones o titularidades cuya realidad interna desconoce ${ }^{75}$.

De este modo, se tienden a proteger todos aquellos casos e i $\mathrm{n} s \mathrm{t}$ i $\mathrm{t} u \mathrm{t}$ o $\mathrm{s}$ en los que se exterioriza una c $\mathrm{r}$ e í b l e declaración hacia los terceros, y que tienen como base el comportamiento del sujeto que la emite. En este contexto, el tercero soporta de buena fe las consecuencias del obrar ajeno, creyendo como verdadero aquello que se le presenta de forma verosímil. Esta circunstancia lleva inexorablemente -ya sea por disposición legal o jurisprudencial, según corresponda-, a privilegiar el interés de los terceros o de las partes afectadas fundamentado en la objetividad de la situación aparente, prescindiendo de esta forma del obrar que haya tenido el auténtico titular ${ }^{76}$.

Las consideraciones anteriores, encuentran diversos supuestos dentro de la generalidad del ordenamiento jurídico ${ }^{77}$. Es decir, la alternativa de protección de la apariencia no es una posibilidad utilizada solamente por el Derecho laboral sino que, por el contrario, ella reconoce la misma lógica en otras parcelas del ordenamiento, sobre todo en el ámbito civil ${ }^{78}$ y comercial ${ }^{79}$. Más aún, muchos de esos casos a pesar de que no admiten expresamente la tesis de la apariencia, han tenido que otorgar determinados efectos normativos a situaciones complejas ya sea en la adquisición de derechos o en la sanción de la actuación simulada.

${ }^{74}$ Jordano BAREA, Juan B., La teoría del heredero aparente y la protección de los terceros, ahora en AA. VV., Estudios jurídicos en homenaje al profesor Federico De Castro (Madrid, Tecnos, 1976), II, pp. 43 y 45; y TALón MARTínez, Francisco, La apariencia jurídica, en Revista Jurídica de Cataluña, 51(1952) 69, pp. 369-370.

75 Ángel YagüEZ, Ricardo de, Apariencia jurídica, cit. (n. 65), p. 21.

${ }^{76}$ Talón Martínez, Francisco, cit. (n. 74), pp. 372-373.

77 Véase el "Prólogo" de Luis Díez-Picazo a la obra de WieAcker, Franz, El principio general de la buena fe (Madrid, Civitas, 1977), p. 11; y Pla Rodríguez, Américo, Los principios, cit. (n. 4), pp. 266-267.

${ }^{78}$ LASARTE, Carlos, Sobre la integración del contrato: la buena fe en la contratación (en torno a la Sentencia del T. S. de 27 de enero de 1977), en Revista de Derecho Privado, 64 (enero de 1980), p. 76.

79 Prado Puga, Arturo, Distinción conceptual entre los poderes aparentes y los poderes tácitos: un ensayo de aplicación al factor o gerente, en BARROs BOURIE, Enrique (coordinación), Contratos (Santiago, Editorial Jurídica de Chile, 1991, pp. 83 ss. 
En esta perspectiva cabe destacar, por ejemplo, las donaciones hechas simuladamente bajo apariencia de otro contrato; los supuestos de heredero y acreedor aparente; el matrimonio putativo; las actuaciones del $\mathrm{f} \mathrm{u} \mathrm{n} \mathrm{c}$ i o $\mathrm{n}$ a $\mathrm{r}$ i o d e h e c h o en la esfera administrativa; el mandatario aparente; la simulación de delitos; o el caso del factor notorio a que se refiere el artículo 286 CCom., entre otras varias alternativas. En la mayor parte de estos supuestos, el ordenamiento jurídico razona con la misma lógica que lo ha hecho la jurisprudencia en el ámbito laboral, toda vez que se parte de la base de que quien crea y permite conscientemente una apariencia verosímil, se encuentra obligado a respetar los efectos que se derivan de dicha situación. Y si no se acepta la apariencia, entonces se sanciona el actuar aparente de conformidad a la ley.

En el fondo, como puede fácilmente concluirse, todos estos casos evidencian una externalidad jurídica determinada, en que una persona se comporta en calidad de titular de un derecho o parece fundadamente serlo, aunque en definitiva el titular real sea otra persona. Ante él se presenta el deudor de la obligación o un tercero interesado en el acto jurídico en cuestión que, actuando de buena fe, tiene razones suficientes para estimar que esa persona es efectivamente el titular del derecho esgrimido. Es decir, la persona obligada al cumplimiento de una obligación, o el tercero, ignoran legítimamente la verdadera cualidad del otro sujeto.

Los casos de apariencia jurídica concurren siempre que se verifique un fenómeno, materialmente presente e inmediatamente real, que a su vez deja al descubierto otro hecho que no reúne dichas características, a través de signos y relaciones de significación socialmente apreciables ${ }^{80}$. La apariencia, de este modo, produce y oculta la consabida discordancia entre la situación exteriorizada y la situación real, generando un estado de ficción ${ }^{81}$.

Como ya se dijo, en los ordenamientos jurídicos no existe por regla general una elaboración sistemática ni unitaria del problema de la apariencia ${ }^{82}$. Salvo el caso de ciertos preceptos específicos del Derecho común, o algunas referencias tangenciales del Derecho comparado, la tendencia es a que sean la jurisprudencia y la doctrina quienes se encarguen de regular los efectos de este tipo de actuaciones ${ }^{83}$. En esa línea, al menos en el ordenamiento chileno, el Derecho del Trabajo se ha convertido en un verdadero adalid en la búsqueda de mecanismos de protección frente a situaciones ilegítimas de apariencia laboral. Ello se ha

${ }^{80}$ Amorós Guardiola, Manuel, El acreedor aparente, en AA. VV, Estudios jurídicos en homenaje al profesor Federico De Castro (Madrid, Tecnos, 1976), I, pp. 61 y 75.

${ }^{81}$ Herrero Nieto, Bernardino, cit. (n. 6), pp. 19 y 65.

${ }^{82}$ Véase, por todos: Ángel YagüEz, Ricardo de, Apariencia jurídica, cit. (n. 65), pp. 25 y 27.

${ }^{83}$ Borrajo Dacruz, Efrén, El abuso de derecho, cit. (n. 12), pp. 2-3. 
traducido, en algunos casos, en que la jurisprudencia termine privilegiando la externalidad ${ }^{84}$; pero en otros, se ha argüido el denominado principio de la realidad para $\mathrm{r}$ o m p e $\mathrm{r}$ dicha externalidad y justificar la indagación de los hechos por sobre los documentos, los acuerdos, o las meras apariencias ${ }^{85}$.

Lo que sucede es que en el ámbito de las relaciones de trabajo, el esquema de la apariencia jurídica podría llevar a suponer, entre otras cosas, que toda persona que se presenta ante el trabajador en calidad de empleador, o como representante legal o voluntario de éste, se encontrará obligado no sólo a exigir la prestación del dependiente, sino que, además, a cumplir con las deudas que surjan del contrato de trabajo. De este modo, el empleador laboral ante los ojos del trabajador sería, en principio, aquella persona que ejerce aparentemente las facultades directivas, y que, en consecuencia, se relaciona directa o indirectamente con el personal, sin tomar en consideración q u i é n e s el verdadero

${ }^{84} \mathrm{Un}$ interesante caso jurisprudencial puede consultarse en la sentencia de la Corte Suprema de 12 de septiembre de 1985, en Gaceta Jurídica, 63 (1985), pp. 76 ss., en la cual la Corte acogió un recurso de queja, y confirmó el fallo de primera instancia dictado por el tribunal laboral. En la sentencia del tribunal a quo, el juez del trabajo concluyó que no es lo mismo contratar en nombre y representación del mandante a hacerlo por encargo del mismo, "pues contratando de la primera manera los efectos del acto jurídico se radican en el patrimonio del mandante supuesto de obrar dentro de los limites del mandato. Pero, al hacerlo de la segunda forma el mandatario, y dado que la facultad de representar no es de la esencia del mandato, lo está haciendo a nombre propio, produciéndose efectos jurídicos sólo entre mandatario y los terceros contratantes, es decir, en esta segunda situación el acto no empece al mandante, evidentemente sin perjuicio de los derechos que puede hacer valer en contra de su mandatario. De consiguiente, actuando de la última forma, la demandada no ha podido sino quedar obligada a cumplir lo pactado con el actor".

${ }^{85}$ Véase la sentencia dictada por la Corte de Apelaciones de Santiago de 16 de diciembre de 1983, en Gaceta Jurídica, 43 (1983), p. 100. En dicho fallo, la Corte desestima la posibilidad de que dos jugadores de fútbol de un club profesional (Santiago Morning) mantengan vínculo laboral con la Asociación Central de Fútbol de Chile. Y agrega en p. 101: " $6^{\circ}$. Que no obsta a la conclusión anterior el hecho de contener los contratos de trabajo aludidos el timbre de la Asociación demandada; ni el informe evacuado por ésta a fojas 44 en que da cuenta de haber pagado determinadas remuneraciones a los señores Cruz y Espinoza, con cargo al Club, y de haber enterado imposiciones y cancelado las cargas familiares que expresa, en relación con las mismas personas; ni los oficios de la Caja de Empleados Particulares agregados a fojas 53 y 55, que dan cuenta del Registro de expediente de Asignación Familiar [...] bajo el titulo de la ACF como empleador, por carecer, todos estos antecedentes, del contenido substantivo de un contrato de trabajo, generador necesario de las obligaciones laborales que se demandan". Véanse, en el plano doctrinal, y en lo que respecta a la determinación del verdadero contenido del contrato de trabajo: Carballo Mena, César, cit. (n. 40), pp. 209-210; García Pilueras, Manuel, cit. (n. 14), pp. 244-245; LoREnZetTI, Ricardo Luis, cit. (n. 30), pp. 285-286; y LUjÁN Alcaraz, José, cit. (n. 39), p. 97. 
titular del ámbito de organización y dirección en el cual se prestan los servicios ${ }^{86}$. Se configuraría, por tanto, una situación jurídica que no es detentada por el verdadero titular.

Para resolver estos problemas de determinación empleadora se tendrá que recurrir a una serie de indicios que permitan dilucidar los extremos casuísticos. Dichos extremos se moverán dentro de una gama de posibilidades y matices que obligan a investigar la eventual comunicabilidad de responsabilidades, como por ejemplo cuando la contratación de los trabajadores por el sujeto intermediario se hace a sabiendas del titular principal o con el consentimiento de éste ${ }^{87}$, a pesar de que el intermediario no se encuentra expresamente autorizado para actuar en nombre del principal ${ }^{88}$; o cuando la contratación se lleva a cabo por un empresario autónomo jurídicamente, pero integrado en una agrupación económica.

Todo lo anterior permite sostener que el problema de la apariencia encuentra una íntima vinculación con los eventuales fraudes que se puedan producir en la figura del empleador ${ }^{89}$. Cuando el trabajador ejecuta su prestación movido por una justificada creencia de que aquél con quien se relaciona es efectivamente el titular de la actividad productiva, se debe precisamente a que el presunto empleador ejecuta una serie de actos que manifiestan un a $\mathrm{n}$ i $\mathrm{m}$ u s determinado y que crean una presumptio iuris tantum en el concepto general de los demás ${ }^{90}$. A ello se une el hecho de que muchas veces el trabajador no sabe a ciencia cierta si el empleador es una persona natural o jurídica, o si es de derecho público o privado; ${ }^{91}$ simplemente ejecuta las labores en la creencia de que aquél que aparece investido bajo la condición de empleador laboral efectivamente lo es. Esto viene a explicar, en parte, que se sigan acatando las instrucciones directivas de la persona que se halla pacíficamente en posesión de una herencia, o al administrador que ha sido removido sin conocimiento del trabajador, ya que en la práctica son ellos quienes aparecen ante los ojos de éste como el verdadero sujeto del contrato de trabajo. De allí que el artículo 4 , inciso $1^{\circ} \mathrm{CT}$. establezca una presunción de derecho en orden a que representa al empleador aquél que

${ }^{86}$ Véase, por ejemplo, la sentencia de la Corte de Apelaciones de Santiago, de 25 de agosto de 1984 , la cual validó la notificación de una demanda laboral al administrador de un establecimiento comercial "pues (éste) dirigía o administraba la empresa o establecimiento para la cual laboraban los actores", en Gaceta Jurídica, 50 (1984), p. 162.

${ }^{87}$ Gordillo, Antonio, La representación aparente. Una aplicación del principio general de protección de la apariencia jurídica (Sevilla, Publicaciones de la Universidad, 1978), pp. 45-46; y Herrero Nieto, Bernardino, cit. (n. 6), p. 93.

${ }^{88}$ Pla Rodríguez, Américo, Los principios, cit. (n. 4), pp. 294-295.

${ }^{89}$ Galiana Moreno, Jesús María, cit. (n. 10), pp. 460 ss.

${ }^{90}$ Jordano Barea, Juan, cit. (n. 74), pp. 4 y 6; y Talón Martínez, Francisco, cit. (n. 74), p. 369.

${ }^{91}$ Pla Rodríguez, Américo, Los principios, cit. (n. 4), p. 255. 
ejerce habitualmente funciones de dirección o a dministración por cuenta o representación de una persona natural o jurídica.

En síntesis, la protección de la apariencia implica, de este modo, una medida en favor de la equidad -entendida ésta como una perspectiva de la justicia-, en que comparada la situación de los diversos sujetos que concurren en la actuación jurídica, el ordenamiento o la jurisprudencia, en su caso, optan en favor de aquella parte que se estima más afectada como en determinados supuestos sería el trabajador.

\section{Requisitos para que el trabajador pueda beneficiarse de la situación} aparente.

De todo lo expuesto hasta ahora queda pendiente determinar en que casos el trabajador puede beneficiarse con la protección de la apariencia, o si, por el contrario, ello ocurrirá en cualquier supuesto. Para arribar a una respuesta adecuada es necesario analizar dos circunstancias: la buena fe del trabajador y la verdadera existencia de una situación aparente. Dichos elementos deben concurrir conjuntamente para que un sujeto pueda beneficiarse de la apariencia. Por tanto, aquí no basta la simple buena fe, o una externalidad determinada, ya que ambos requisitos se requieren mutuamente.

a) Buena fe por partedel trabajador.Labuenafe constituye uno de esos principios jurídicos que se entienden mejor de lo que se definen $^{92}$. En virtud de ella, trabajador y empleador se encuentran obligados a actuar conforme a criterios de honradez y lealtad en el desarrollo del contrato, corrigiendo los excesos del individualismo jurídico ${ }^{93}$. Estas exigencias derivadas de la buena fe, permiten sostener que en las obligaciones de ambos contratantes pervive el deber de no defraudar a la contraparte ${ }^{94}$.

A mayor abundamiento, la buena fe supone proteger una serie de relaciones jurídicas, muchas veces al margen del Derecho positivo, en atención a razones de carácter moral o de tráfico social ${ }^{95}$. Y esa protección surge precisamente porque uno de los sujetos del contrato tiene la creencia, nacida de un error excusable, de que lo que se le representa es lícito y que su conducta se ajusta plenamente a Derecho ${ }^{96}$. Si existiera mala fe, sería imposible reclamar la protección del ordenamiento ya que -más allá de los límites que impone un

92 González Rodríguez, Manuel, Bocetos jurídicos: la buena fe y la seguridad jurídica, en Anales de la Academia Matritense del Notariado, 3 (1946), p. 327.

${ }^{93}$ Montoya Melgar, Alfredo, La buena fe en el Derecho del trabajo (Madrid, Tecnos, 2001), p. 17.

${ }^{94}$ Irureta Uriarte, Pedro, cit. (20), p. 150.

${ }^{95}$ González Rodríguez, Manuel, cit. (n. 92), p. 328.

${ }^{96}$ Lasarte, Carlos, cit. (n. 78), p. 75. 
correcto obrar- el ejercicio del derecho se tornaría inadmisible y antijurídico ${ }^{97}$. En definitiva, lo que verdaderamente se está vetando es el aprovechamiento ilícito de una situación determinada, pretendiendo sacar ventajas indebidas de una cuestión conocida.

En principio, y por aplicación de las reglas generales del Derecho común, quien confía en la apariencia confía en algo más que la simple declaración de voluntad ${ }^{98}$. Confía verdaderamente en que la persona que se le presenta en calidad de titular de una determinada condición jurídica - la de empleador, por ejemplo- lo es efectivamente en la realidad. Para ello, como es lógico, se requiere que el tercero o la contraparte se encuentren en una lícita posición de creencia a objeto de que lo representado se condiga exactamente con la intencionalidad. Ese requisito, de carácter técnico jurídico, es el que se denomina como el de la buena fe subjetiva.

En el plano de las relaciones laborales, la concurrencia de la buena fe permite configurar al trabajador como un sujeto que legítima y confiadamente se relaciona con el supuesto empleador, aun cuando éste no lo sea jurídicamente. La buena fe acarrea de este modo la p u r i f i c a c i ó n de la situación irregular y no ajustada plenamente a Derecho.

Esta circunstancia lleva a que el ordenamiento legal favorezca al trabajador otorgándole determinados efectos al acto celebrado, y que de otra manera no podrían alcanzarse $e^{99}$. La buena fe, por tanto, excluye al trabajador de cualquier grado de c u l p a b i l i d a d que le impidiese el goce efectivo de los derechos que creyó adquirir con la actuación del empleador aparente, ya que en definitiva la acción representativa -repetida y pública- por parte de éste, y la tolerancia de la misma, sin oposición ni protesta por parte del titular oculto, llevan ineludiblemente a proteger al trabajador que actuó de buena $\mathrm{fe}^{100}$.

Dicha protección se fundamenta precisamente en un actuar correcto, que lleva al trabajador a confiar en la apariencia empleadora creada por otro, sin que exista fraude o dolo en su creencia ${ }^{101}$. Lo importante, en todo caso, es que

${ }^{97}$ Véase el "Prólogo" de Díez-Picazo a la obra de Wieacker, cit. (n. 77), p. 20.

${ }^{98}$ Gordillo, Antonio, La representación, cit. (n. 87), p. 143.

${ }_{99}$ Véase, por ejemplo, la sentencia de la Corte de Apelaciones de Santiago, de 24 de abril de 1995, en Gaceta Jurídica, 178 (1995), p. 175: "Es ineficaz la comunicación incompleta de un cambio de representante legal de una sociedad (...) si no se señala además el nombre del nuevo representante. Debe entenderse en tal virtud que la sociedad continua representada por las mismas personas indicadas en la última comunicación efectuada $[\ldots] "$.

${ }^{100}$ Véase, en relación con el Derecho común: Gordillo, Antonio, Comentario a la STS de 3 de junio de 1991, en Cuadernos Civitas de Jurisprudencia Civil (abril-agosto de 1991), p. 650.

${ }^{101}$ Véase la sentencia de la Corte de Apelaciones de Concepción, de 14 de agosto de 2002, en Gaceta Jurídica, 266 (2002), pp. 204 ss. 
en virtud de la buena fe el trabajador cumple regularmente la prestación a la cual se encuentra obligado por el contrato, independientemente de que con posterioridad se concluya que la condición de empleador debe ser atribuida a otra persona. Por ejemplo, si un empleador fallece y su presunto heredero toma posesión de la herencia, continuando con la actividad desarrollada en la empresa, el trabajador se encuentra obligado a ejecutar las labores que se le imponen en razón del contrato, siempre y cuando haya actuado por criterios de buena $\mathrm{fe}^{102}$. De otra forma se estaría protegiendo a quien, habiendo conocido la situación real, se acoge maliciosamente a la aparente a fin de obtener una ventaja determinada ${ }^{103}$.

Por ello, hay que tener presente que para que se configure la situación de apariencia es preciso que el trabajador se encuentre en una situación de creencia o ignorancia compatible con un actuar honesto, no fraudulento por parte de éste. En este orden de ideas, si el error en la apariencia no es imputable al trabajador, y éste ha actuado diligentemente y de acuerdo a los criterios de la buena fe, entonces el ordenamiento jurídico del trabajo se despliega y lo protege en su creencia. Por el contrario, si lo que existe es un conocimiento cierto del fraude o del abuso que se esconde detrás de la apariencia, entonces difícilmente el ordenamiento jurídico podrá amparar dicha situación ${ }^{104}$.

En el fondo, lo que hace el ordenamiento jurídico es otorgarle al trabajador de buena fe una protección sobre el derecho o expectativa que surge a raíz de la actuación del empleador ficticio, concediéndole frente al estado aparente un resguardo más profundo de sus intereses ${ }^{105}$. Hay, por tanto, un principio de protección de la confianza legítimamente adquirida, que juega como un requisito indispensable ante situaciones extraordinarias o anómalas.

Con todo, el criterio anterior debe ser matizado. Si bien es cierto que la buena fe constituye un requisito esencial a la hora de desplegar la protección sobre el trabajador afectado, no hay que olvidar que existen situaciones en que aun cuando no concurra este elemento igual tendrá que existir algún grado de protección. Así, por ejemplo, el hecho de que el trabajador conozca la circunstancia de que su e m p l e a d o r es una sociedad irregular no

102 Véanse: Amorós Guardiola, Manuel, cit. (n. 80), p. 51; Cabanellas, Guillermo, cit. (n. 23), II,3, p. 35. Asimismo, a nivel jurisprudencial, la sentencia de la Corte de Apelaciones de Santiago, de 11 de noviembre de 1988, en Revista de Derecho y Jurisprudencia, 85 (1988), sección $3^{\text {a }}$ p. 246. Por el contrario, si el heredero asume la condición de empleador sin y justificar adecuadamente su condición, el trabajador actuaría irresponsablemente si ejecuta la prestación en referencia a una persona que no ha acreditado en la debida forma su condición de sucesor del empleador fallecido.

${ }^{103}$ Díez-Picazo, Luis - Gullon, Antonio, cit. (n. 10), II, p. 82; y Talón MarTÍNEZ, cit. (n. 74), p. 374.

${ }^{104}$ Irureta Uriarte, Pedro, cit. (n. 20), p. 139.

105 Talón Martínez, cit. (n. 74), p. 368. 
puede invalidar el contrato, ya que en definitiva lo que prima es la prestación efectiva de los servicios para un ente sin personalidad jurídica ${ }^{106}$. Asimismo, existen situaciones en que el trabajador se siente obligado a aceptar la situación anómala por temor a sanciones o a la pérdida del empleo ${ }^{107}$; o, también, por ignorancia sobre la verdadera fisonomía jurídica de su empleador ${ }^{108}$. $\mathrm{O}$, incluso, aun cuando no concurra una le gít i m a ig n o r a n c i a por parte del trabajador, de igual forma el ordenamiento jurídico prefigura los efectos de la situación aparente, sea por actuación simulada o porque ella degenera en un acto prohibido por la ley.

En consecuencia, todas estas situaciones tendrán que ser analizadas caso a caso, debiendo el juez evaluar las circunstancias concurrentes a pesar de no estar presente el requisito de la buena fe, o bien cuando éste se encuentre notoriamente aminorado.

b)A pariencia externa de ostentar la condición $\mathrm{d}$ e e m p l e a d o r. Un segundo requisito exigido para que se verifique la doctrina de la apariencia jurídica en el ámbito laboral consiste en el hecho de que el sujeto que pretenda ocupar la posición de empleador ejecute actos objetivos que induzcan a dicha conclusión. Es decir, que se prefigure externamente, y de modo verosímil, la figura del empleador. En este orden de ideas, la apariencia deja el descubierto la realización de actos externamente creíbles pero que están en completo divorcio con la realidad.

$\mathrm{Al}$ producirse un actuar creíble, el ordenamiento jurídico se despliega en la protección del otro contratante toda vez que lo que no puede permitir es que se genere en él la convicción legítima de un cierto estado de cosas, para luego defraudarlo. Si alguien ha confiado razonablemente en una determinada manifestación jurídica y se ha comportado conforme a ella, entonces el ordenamiento jurídico le reconoce el derecho a contar con tal manifestación aun cuando ella no se corresponda con la realidad ${ }^{109}$.

En muchos casos, la existencia de una buena o mala fe por parte del em-

${ }^{106}$ Galiana Moreno, Jesús María, cit. (n. 10), pp. 451-452.

${ }^{107}$ Cabanellas, Guillermo, cit. (n. 23), II,1, p. 348; Galiana Moreno, Jesús María, cit. (n. 10), p. 449; y OJEDA Avilés, Antonio, La renuncia de derechos, cit. (n. 44), pp. 122 y 127.

${ }^{108}$ Pero es que resulta que, además, tal como lo ha recalcado Gordillo, Manuel, Comentario, cit. (n. 100(, p. 650, debido a la implicancia consciente del dominus negotii en la species facti aparentemente representativa, "sería objetivamente ilícito y desleal (contrario a la buena fe en sentido objetivo) que el mismo que ha venido tolerando la actuación de quien por él y para él venía actuando, pudiera volverse ahora contra sus propios actos y pretendiera desconocer las consecuencias de lo que previamente había consentido".

109 Véase: Ángel Yagüez, Ricardo de, Apariencia jurídica, cit. (n. 65), p. 14; y también Irureta Uriarte, Pedro, cit. (n. 20), p. 141. 
pleador ficticio no tiene tanta importancia en lo que respecta al trabajador. Sin embargo, dicho a n i m u s defraudatorio sí tendrá relevancia, por ejemplo, en el supuesto de que el verdadero empleador pretenda determinar el grado de responsabilidad derivados de los actos ejecutados por el sujeto aparente, más aun si el trabajador ha actuado de buena $\mathrm{fe}^{110}$. En este sentido, el empleador aparente actuaría maliciosamente cuando ha entrando en la "posesión" de tal sin ningún título, o con un título simulado, o con un título cuyos vicios conocía; o, también, cuando el empleador ficticio pretenda dicha condición alegando error de hecho o de derecho, si en contra de él se demuestra su dolo, la conciencia de su ilegitimidad, o la culpa grave por tratarse de error inexcusable ${ }^{111}$. La consecuencia más inmediata de este obrar de mala fe es que el empleador aparente no podrá beneficiarse de la externalidad ilícitamente creada, ya que ello se opondría frontalmente con el ordenamiento jurídico, y en especial con el Derecho del Trabajo, que se encuentra estructurado en orden a cerrar el camino a cualquier pretensión de aprovechamiento ilícito ${ }^{112}$.

Lo que subyace, por tanto, en cada una de estas hipótesis, es que perfectamente puede presentarse una relación de trabajo con dos sujetos claramente distintivos: por una parte, existe un empleador ficticio, que de buena o mala fe aparenta tener la condición de sujeto del contrato de trabajo -aunque en definitiva jamás adquiera ese papel-induciendo a la opinión general, y al trabajador en particular, a la creencia razonable de que él es el empleador real; y, por la otra, un trabajador que da cumplimiento a su prestación animado por la legítima creencia (buena fe subjetiva) de que presta servicios para el verdadero sujeto empleador del contrato de trabajo. De este modo, la tesis de la apariencia en la figura del empleador se termina verificando en todos aquellos casos en que ésta no coincide con la realidad, concurriendo circunstancias objetivas que dan credibilidad al hecho externo ${ }^{113}$.

Por último, y aun cuando se acepte que la falta de maquinación dolosa no es esencial en la configuración del fraude ${ }^{114}$, no cabe duda de que aquella es

${ }^{110}$ En esta perspectiva: Galiana Moreno, Jesús María, cit. (n. 10), p. 447.

${ }^{111}$ Díez-PiCazo, Luis - Gullón, Antonio, cit. (n. 10), II, pp. 81-82; y Jordano BAREA, Juan, cit. (n. 74), p. 14.

112 Pla Rodríguez, Américo, Los principios, cit. (n. 4), p. 260; Talón MartíNEZ, cit. (n. 74), p. 374.

113 Amorós Guardiola, Manuel, cit. (n. 80), pp. 76-77; y Jordano Barea, Juan, cit. (n. 74), pp. 7-8.

${ }^{114}$ Por lo demás, hay que reiterar que la doctrina mayoritaria estima que al constituir el fraude en su noción moderna una infracción del deber jurídico de cumplimiento de las normas dictadas, ya no se atiende a la intencionalidad, sino que al resultado. Lo que se sanciona, en definitiva, es el resultado prohibido por el ordenamiento jurídico o contrario a él. Véanse, entre otros: Borrajo DaCruz, Efrén, El abuso de derecho, cit. (n. 12), p. 2; García ViÑas, Jordi, cit. (n. 14), p. 813; López López, Julio, cit. (n. 
necesaria para la acreditación o prueba de una actuación de mala fe, destinada a dañar a terceros ${ }^{115}$. El problema, eso sí, es que la mayor parte de las veces la simulación fraudulenta va acompañada de una serie de actos tendentes a hacer desaparecer todos los vestigios de la simulación, razón por la cual habrá que remitirse obligadamente a la prueba indirecta de las presunciones. No hay que olvidar que este sistema probatorio opera fundamentalmente en supuestos en los que exista una necesidad de otros medios de prueba, toda vez que ella resulta especialmente difícil ${ }^{116}$.

\section{La apariencia en los casos del sujeto interpuesto y del factor notorio.}

Las hipótesis de apariencia empleadora revisten un sinnúmero de alternativas, tan complejas como la misma práctica laboral. Basta que el trabajador se relacione con un sujeto que aparenta tener la condición de empleador para que se ponga en movimiento todo un entramado de normas y de criterios judiciales destinados a precisar la exacta identidad del sujeto responsable.

El análisis de esta materia debe partir, en todo caso, de la regla general en orden a que la calidad de empleador la tiene el titular de la actividad productiva que, en cuanto tal, recepciona los servicios prestados por el trabajador. Ese es el telón de fondo sobre el que se mueve el Código del Trabajo, y sobre el cual se construyen los supuestos enunciados por el artículo 3, letra a), del texto legal antes mencionado. Una cosa es el titular, y otra distinta es que haya un representante del titular (hipótesis en la cual se sitúa el inciso primero del artículo $4 \mathrm{CT}$.).

Sin embargo, entre este criterio y la realidad pueden existir una serie de variantes que distorsionan o tergiversan la regla general, requiriéndose un estudio más profundo en cuanto a lave $\mathrm{rd}$ a d e $\mathrm{r}$ a $\mathrm{n}$ a t u ral e za $\mathrm{d}$ e $l$ a s c o s a $s$. Una de esas hipótesis se verifica, sin ir más lejos, en los supuestos de transmisión de empresas, que por lo general pueden llegar a provocar una errónea creencia en el trabajador ${ }^{117}$. Este, ajeno a toda clase de mutaciones jurídicas en la estructura empresarial, en innumerables ocasiones termina

17), p. 339; y Ugarte Cataldo, José Luis, cit. (n. 19), p. 110. En el ámbito civil, por todos: Batlle VázQuez, Manuel, cit. (n. 10), p. 115; Castán Tobeñas, José, cit. (n. 1), I, p. 574; y NAVARro Fernández, José Antonio, El fraude de ley: su tratamiento jurisprudencial (Madrid, Montecorvo, 1988), p. 83.

${ }^{115}$ Véanse, por todos: CASAs BAAmONDE, María Emilia, cit. (n. 16), p. 88; Galiana Moreno, Jesús María, cit. (n. 10), pp. 448-449; García Valverde, María D., cit. (n. 9), p. 109; y García Viñas, Jordi, cit. (n. 14), p. 832.

${ }^{116}$ Rodríguez-Piñero Royo, Miguel, La presunción de existencia del contrato de trabajo (Madrid, Civitas, 1985), p. 57.

${ }^{117}$ Albiol Montecinos, Ignacio, Aspectos laborales de la transmisión de empresa (Madrid, Servicio de Publicaciones Ministerio de Trabajo y Seguridad Social, 1984), p. 78 . 
desconociendo la verdadera identidad de su empleador, cuestión que obliga a proteger sus derechos dentro del esquema de la relación laboral ${ }^{118}$. En todos estos ámbitos, el trabajador se sitúa como parte afectada por las identidades, apariencias y mutaciones que afectan al empleador, concluyendo una serie de actos jurídico-laborales en razón precisamente de la apariencia creada por el pretendido empleador y cuya verdadera situación jurídica el trabajador desconocía, al menos inicialmente. El principio de interpretación general para cada una de estas hipótesis es que el trabajador no tiene porqué entenderse obligado a indagar sobre la exacta identidad o naturaleza de la persona con la cual contrató laboralmente, más aun si dicha indagación supondría conocer una serie de entramados jurídicos y circunstancias que se han tratado de ocultar. Lisa y llanamente, los criterios de la recepción efectiva de los servicios y de la titularidad podrían bastar para resolver estos problemas ${ }^{119}$.

No obstante, existen dentro de la práctica laboral dos situaciones que merecen un análisis especial, y que pueden ser reconducidas a la figura del sujeto interpuesto o del factor notorio: o existe una apariencia subjetiva, representada por la interposición ficticia de una persona que finge tener la calidad de empleador del trabajador; o, por el contrario, aun cuando existe una apariencia determinada, se verifica la figura del representante sin poder o falso procurador.

a) E l sujeto in te r p u est o. Lacelebración de cualquier contrato puede dar origen a la interposición de una persona extraña. Los verdaderos contratantes no se ven ni se dan a conocer, ya que ambas partes contratan a través de un intermediario ${ }^{120}$. En algunos casos, esa intermediación no sólo es válida, sino que además es querida por las partes o aceptada por el ordenamiento jurídico; pero en otras, en cambio, la interposición podrá suponer una apariencia de obrar propio, aun cuando lo que existe es una actuación por encargo y en provecho de un sujeto diverso.

En el ámbito de las relaciones de trabajo, el intermediario actúa con una titularidad formal, que le permite ocupar la posición de empleador, a pesar de que el verdadero destinatario de la prestación del trabajador es un tercero que

118 Monereo Pérez, José Luis, Las relaciones de trabajo en la transmisión de la empresa (Madrid, Servicio de Publicaciones Ministerio de Trabajo y Seguridad Social, 1987), p. 130.

119 Véase, a raíz de esto, la regla contenida en el inciso segundo del artículo 4 CT.: "Las modificaciones totales o parciales relativas al dominio, posesión o mera tenencia de la empresa no alterarán los derechos y obligaciones de los trabajadores emanados de sus contratos individuales o de los instrumentos colectivos de trabajo, que mantendrán su vigencia $y$ continuidad con el o los nuevos empleadores".

${ }^{120}$ Núñez Lagos, R., Mandatario sin poder, en Revista de Derecho Privado, 30 (1946) 354, p. 610. 
permanece oculto. La titularidad aparente encubre o esconde al titular real de las relaciones jurídicas ${ }^{121}$. En este esquema, la amalgama de negocios jurídicos deja al descubierto una pluralidad de partes que reflejan un sujeto intermediario, una persona interpuesta, la contraparte en la convención, y un tercero, todos los cuáles se encuentran afectados por un sólo vínculo jurídico ${ }^{122}$.

La interposición, como se sabe, es una combinación de negocios jurídicos que admite dos tipos de figuras: la interposición real y la interposición ficticia ${ }^{123}$. En virtud de la primera, lo que se produce es una intromisión de un sujeto ajeno a la relación, que pasa a ocupar la posición jurídica de una de las partes. En estos casos, el sujeto interpuesto actúa en nombre e interés propio, recayendo sobre él los efectos del acto jurídico que ha de celebrar con el interponente. Por cierto, esto no impide que con posterioridad se pueda producir una transmisión de derechos hacia la persona que permanece oculta; pero en principio, la interposición real trae como consecuencia que el titular aparente se convierta a la vez en titular real. Lo que ocurre en la práctica, es que esta figura termina calzando con el mandato o la representación, asumiendo el interponente la condición de mandante con respecto a los actos que celebra su mandatario (persona interpuesta). En esta hipótesis se encontraría, también, la contratación de trabajadores para cederlos a otro, siempre que el verdadero titular participe de forma activa en el acto ${ }^{124}$.

La interposición ficticia, por su parte, también provoca la intromisión de un sujeto entre los verdaderos titulares de la relación jurídica. Sin embargo, en este caso lo que existe es una apariencia de titularidad por parte del interpuesto, sin sustento real, debiendo recaer todos los efectos de la relación jurídica en el interponente, titular efectivo del negocio jurídico ${ }^{125}$. Esta figura se entronca perfectamente con aquella que, en el Derecho privado, se conoce con el nombre de t e $\mathrm{s} \mathrm{t}$ a $\mathrm{f}$ e $\mathrm{r} \mathrm{r}$ o; es decir, una persona que presta su identidad en un contrato o negocio que en verdad afecta a otra persona. Por tanto, lo que existe es un mero contratante fingido que, al prestar su nombre, no hace más que provocar una interposición ficticia de persona.

Llevado esto al ámbito de la figura empleadora, la interposición ficticia se

${ }^{121}$ Véanse, por todos, Martin VAlverde, Antonio, cit. (n. 55), p. 33; y RodríGUez-Piñero Royo, Miguel, Cesión de trabajadores y empresas de trabajo temporal (Madrid, Centro de Publicaciones Ministerio de Trabajo y Seguridad Social, 1992), p. 22.

${ }^{122}$ Rodríguez Ramos, María José, cit. (n. 12), p. 31.

${ }^{123}$ García Murcia, Joaquín, El trabajo en contratas y la cesión de mano de obra en el Estatuto de los Trabajadores, en Revista de Politica Social, 130 (1981), p. 67.

${ }^{124}$ Véanse los artículos 183-F ss. del CT.

${ }^{125}$ Rodríguez Ramos, María José, cit. (n. 12), p. 32. Véase también: Díez-PiCAzo, Luis - Gullón, Antonio, cit. (n. 10), II, p. 84; Ferrara, Francisco, cit. (n. 5), pp. 273 ss.; y Herrero Nieto, Bernardino, cit. (n. 6), p. 93. 
producirá en el evento de que el empleador real asuma una posición pasiva en el acto que celebra el sujeto interpuesto. Ya sea porque se oculta al titular real, o porque éste cede su posición jurídica a otra persona, aun cuando sigue apareciendo como tal, la interposición provoca una titularidad aparente que oculta al verdadero sujeto contratante ${ }^{126}$. Este prefiere no aparecer en el acto, eludiendo las responsabilidades inherentes a la posición de empleador. De ese modo, se crea un centro artificial de imputación de normas que no evidencia externamente su relación con el titular efectivo ${ }^{127}$. El trabajador, tiene como empleador formal a un sujeto que no ostenta verdaderamente la titularidad de la actividad productiva. Por cierto, el empleador oculto es quien debiera soportar las consecuencias del contrato de trabajo; sin embargo, salvo que sea descubierto, será la persona interpuesta quien se proyecte hacia el exterior como el auténtico sujeto del contrato debido a que su actuación se verifica bajo la cobertura de un acto rigurosamente lícito. Es por esto por lo que, e $\mathrm{l}$ i $\mathrm{m}$ i n a d a la persona interpuesta se anuda en toda su magnitud el vínculo contractual entre el empleador efectivo y el trabajador ${ }^{128}$.

Si bien es cierto que todos los fenómenos de cesión de personal participan de una naturaleza interpositoria ${ }^{129}$, no cabe duda de que la cesión ilegal de trabajadores a que se refiere el artículo $183-\mathrm{N}$ del Código podría encuadrarse dentro de una interposición ficticia, que deja en evidencia una simulación relativa destinada a engañar al trabajador. En todo caso, ello no impide que, dada la amplitud actual del precepto legal, se puedan verificar supuestos de cesión subsumibles dentro de la categoría de una interposición real.

b) E l factor notorio. Una segunda alternativa de apariencia empresarial viene dada, sobre todo en el ámbito mercantil, por la figura de un f a c t o r aparente, quien lleva a cabo la actividad de contratación presuntamente para otro empresario, pero sin tener la debida autorización para ello ${ }^{130}$. En estos casos, el sujeto aparenta ser el verdadero mandatario del empleador, de modo tal que el trabajador cree que se contrata a nombre de aquél. Para re-

${ }^{126}$ García Murcia, Joaquín, cit. (n. 123), p. 68; y Martin Valverde, Antonio, cit. (n. 55), p. 35.

${ }^{127}$ Rodríguez-Piñero Royo, Miguel, Cesión de trabajadores, cit. (n. 121), pp. 22 y 23; y Rodríguez Ramos, María José, cit. (n. 12), p. 33 y 88.

${ }^{128}$ Martin Valverde, Antonio, cit. (n. 55), p. 40.

${ }^{129}$ Rodríguez Ramos, María José, cit. (n. 12), p. 36. Véase también: Rojas Miño, Irene, La externalización laboral y la cesión ilegal de trabajadores en el sistema jurídico chileno, en Ius et Praxis XVI (2010) 1, pp. 182 y ss.

${ }^{130}$ Díez-PiCazo, Luis - Gullón, Antonio, cit. (n. 10), I, p. 522. Las hipótesis a este respecto son varias, y se pueden sintetizar en las siguientes alternativas: el poder de representación no existe ni ha existido nunca, la actividad representativa se desarrolla cuando se había extinguido el apoderamiento o, por último, el poder de representación existe pero el acto de contratación laboral excede los límites de dicho poder. 
solver esta situación es preciso determinar, previamente, si el factor ha actuado carente o revestido de notoriedad.

En el primer caso, si el factor llegara a actuar en nombre propio -y no en representación de su principal-, careciendo de la notoriedad exigida por la legislación comercial, tendrá que soportar personalmente los efectos de su actuación ante los trabajadores, de conformidad con lo establecido en el artículo $255 \mathrm{CCom}$. Salvo que se trate de cosas propias del mandante, la actuación del falso procurador genera actuaciones que recaen en su propio patrimonio debido a que él fue quien recibió efectivamente la prestación de servicios. Lo que ocurre es que siempre se deberá entender que quien contrata se presume que lo hace para sí, salvo por cierto que se haga en nombre de otro.

Por el contrario, si el factor actúa revestido de notoriedad suficiente entonces habrá que concluir que quien termina obligándose es su principal, en atención a la debida protección que requiere el sujeto contratante. En razón de lo anterior, la propia legislación comercial ha tenido que señalar que los contratos celebrados por el factor de un establecimiento o empresa fabril o comercial -cuando notoriamente pertenezca a una empresa o sociedad conocidas- se entenderán hechos por cuenta del propietario de dicha empresa o sociedad; aun cuando el factor no lo haya expresado al tiempo de celebrarlos y siempre que estos contratos recaigan sobre objetos comprendidos en el giro y tráfico del establecimiento ${ }^{131}$.

Esta notoriedad que inviste el sujeto contratante, el cual se encuentra unido al principal en virtud de un contrato laboral, implica que los trabajadores que se relacionan con el factor debieran contar en principio con los antecedentes necesarios para saber efectivamente con quien se está fraguando la relación de trabajo. Pero incluso en el supuesto de que el factor contrate en su propio nombre, pero dentro del giro o tráfico de la empresa a la que sirve, de todas formas deberá entenderse que está contratando al trabajador por cuenta y en nombre del verdadero empresario ${ }^{132}$.

$\mathrm{Al}$ respecto, no hay que olvidar que en todos los supuestos en que el Código de Comercio contempla la figura del factor, lo ve como un representante dotado

${ }^{131}$ Desde una perspectiva doctrinaria, véanse, entre otros: Broseta Pont, Manuel, Manual de Derecho mercantil (7a edición, Madrid, Tecnos 1987), pp. 152-153; JimÉnez SÁnchez, Guillermo, Lecciones de Derecho mercantil (reimpresión, Madrid, Tecnos, 1993), p. 93; Martínez Girón, Jesús, cit. (n. 73), p. 52; y URía, Rodrigo, Derecho mercantil (18a edición, Madrid, Marcial Pons, 1991), pp. 54-55.

${ }^{132}$ Véase el artículo $328 \mathrm{~N}^{\circ} 1$ CCom.: "Los factores o dependientes que obraren en su propio nombre quedan personalmente obligados a cumplir los contratos que ajustaren; pero se entenderán que los han ajustado por cuenta de sus comitentes en los casos siguientes: Cuando tal contrato corresponde al giro ordinario del establecimiento que administran". 
de un poder general, que actúa por cuenta y en nombre de su principal ${ }^{133}$. De este modo, dentro de la actividad de la empresa, el factor goza, sin necesidad de un otorgamiento expreso, de los poderes necesarios para el ejercicio de su función ${ }^{134}$. Y ello se ha establecido así, precisamente, para defender a las personas que se relacionan con él -los trabajadores en este caso-, y que no se encuentran capacitados para conocer el ámbito del poder tácita o formalmente otorgado $^{135}$.

En este orden de ideas, la contemplatio domini viene a confundirse con la notoriedad de la condición representativa. Dicha representatividad no sólo quedará al descubierto cuando el factor actúa fo $\mathrm{r} \mathrm{m}$ a $\mathrm{l} \mathrm{m}$ e $\mathrm{n}$ t e en nombre del dominus, sino que también cuando, sin necesidad de ese dato expreso, las circunstancias permiten deducir el carácter representativo de su actuación ${ }^{136}$.

En síntesis, lo que subyace dentro de todas estas alternativas es que el verdadero empleador será aquél que actúa como titular de un determinado ámbito organizativo y que, en tal virtud, recepciona los servicios prestados por el trabajador a cambio de una retribución. Y dicha condición la podrá ejercer personalmente, o bien mediante persona interpuesta que actúa como su representante.

c)La configuración del error en la determinac i ó n d e l e m ple a d o r. En la mayor parte de las hipótesis que hemos planteado hasta ahora, se configura una creencia equivocada del trabajador en lo que respecta a la verdadera identidad de la parte empleadora. Se trata, en definitiva, de un típico caso de error in persona ${ }^{137}$, que afecta al conocimiento que el trabajador tiene del sujeto con quien contrata ${ }^{138}$.

Con todo, los supuestos de equivocación en la persona del empleador requieren de algunas matizaciones. En principio, el error del trabajador no debiera invalidar el contrato, no sólo porque la presunción de laboralidad del artículo $8 \mathrm{CT}$. se aplica en todos sus efectos, sino que además porque el propio inciso primero del artículo 1455 CC. admite que el "error acerca de la persona con quien se tiene intención de contratar no vicia el consentimiento, salvo que la

${ }^{133}$ Prado Puga, Arturo, cit. (n. 79), pp. 90 ss.

${ }^{134}$ Jiménez SÁnCHEZ, Guillermo, cit. (n. 131), p. 93; y MenÉndeZ MenÉndeZ, Aurelio, cit. (n. 73), p. 281. Este último autor agrega en pp. 293 y 294: "La actuación del factor al frente del establecimiento, es decir, dentro de su giro o tráfico, crea una apariencia de poder, y la ley no hace más que fijar ese contenido 'presuntivo' del mismo y sacar las consecuencias".

${ }^{135}$ Uría, Rodrigo, cit. (n. 131), pp. 55-56.

${ }^{136}$ Gordillo, Antonio, La representación, cit. (n. 87), p. 46; también, Broseta Pont, Manuel, Manual, cit. (n. 131), p. 153.

${ }^{137}$ Alonso García, Manuel, Curso de Derecho del trabajo (10ª edición, Barcelona, Ariel, 1987), p. 373.

${ }^{138}$ García Valverde, María, cit. (n. 9), p. 102. 
consideración de estapersona sea la causa principal del contrato". Es decir, cuando el error recae sobre cualidades secundarias, no tomadas como fundamentales por el trabajador, lo normal es que no exista vicio del consentimiento. Por el contrario, sí será causa de nulidad en el evento de que la cualidad personal del empleador haya sido el motivo esencial de la contratación, y entre las cuales se podrían destacar el prestigio, la situación geográfica, o la actividad de éste ${ }^{139}$. En cada uno de estos supuestos, se podría eventualmente alegar error en el consentimiento emitido por el trabajador, ya que éste se habría forjado una imagen equivocada sobre la exacta i $\mathrm{d}$ e $\mathrm{n} \mathrm{t}$ i $\mathrm{d}$ a $\mathrm{d}$ del empleador con quien concierta su compromiso ${ }^{140}$. Y esa imagen equivocada o falso conocimiento, lleva al trabajador a vincularse laboralmente con el empleador ${ }^{141}$.

Todo esto lleva a la necesidad de dilucidar, de forma previa, si la característica intuitu personae opera con respecto al empleador ${ }^{142}$. Sabemos que esta condicionante es más propia del trabajador ${ }^{143}$, pero igual existen situaciones en que las cualidades personales del empleador han contribuido a formalizar el vínculo laboral: por ejemplo, las exigencias profesionales ${ }^{144}$, la consideración que la empresa tiene en el mercado ${ }^{145} \mathrm{o}$, incluso, la capacidad patrimonial ${ }^{146}$, cuestiones todas que llevan al trabajador a formarse una imagen equivocada so-

${ }^{139}$ Molero Manglano, Carlos, cit. (n. 12), p. 261; también, Palomeque LóPEZ, Manuel-Carlos, cit. (n. 46), p. 36.

${ }^{140}$ Sempere Navarro, Antonio-Vicente, Los elementos esenciales del contrato de trabajo en la jurisprudencia, en Montoya Melgar, Alfredo - Martin Valverde, Antonio - Rodríguez-Sañudo GutiérRez, Fermín (coordinadores), Cuestiones actuales de Derecho del trabajo, Homenaje al profesor Manuel Alonso Olea (Madrid, Publicaciones Ministerio del Trabajo y Seguridad Social, 1990), p. 699. Con todo, se ha estimado que el error sobre los motivos generales que se tuvieron para contratar no debieran invalidar el acto jurídico.

${ }^{141}$ García Valverde, María, cit. (n. 9), p. 102. En esa hipótesis estaría, por ejemplo, un trabajador que celebra un contrato para desempeñarse en una empresa de gran categoría, y que con posterioridad se ve obligado a efectuarlo para la persona de uno de los empleados de la misma. Véase: Bayón Chacón, Gaspar - Pérez Botija, Eugenio, Manual de Derecho del trabajo (11 ${ }^{\text {a }}$ edición, Madrid, Marcial Pons, 1977-1978), I, p. 254.

${ }^{142}$ García Valverde, María, cit. (n. 9), p. 103.

${ }^{143}$ Véanse, por todos: Pla Rodríguez, Américo, Curso de Derecho laboral (2a reimpresión, Montevideo, Ediciones Idea, 1990), I,1, pp. 64 y 147; y VÁzQUEZ VIALARD, Antonio, Tratado de Derecho del trabajo (Buenos Aires, Astrea, 1982), 5, pp. 17 y 521 .

${ }^{144}$ Cabanellas, Guillermo, cit. (n. 23), II, 3, p. 36.

${ }^{145}$ VázQuez Vialard, Antonio, cit. (n. 143), III, p. 359.

${ }^{146}$ Bayón Chacón, Gaspar - Pérez Botija, Eugenio, cit. (n. 141), I, p. 254 : “Sin embargo, el error hay que referirlo más a la consideración patrimonial y económica de la empresa que al titular de la misma, de tal manera que si un trabajador cree entrar a trabajar al servicio del constructor de una casa no debe tener efectos invalidantes el 
bre el sujeto contratante. Con todo, no serían protegibles las confusiones sobre la naturaleza privada o pública del empleador, y que técnicamente pueden ser consideradas como una subespecie del error en la cualidad de la persona ${ }^{147}$.

Consecuente con estas consideraciones, habrá que señalar que el error en la identidad del empleador invalidará el contrato sólo en aquellos casos en que las cualidades personales de éste se constituyan razonablemente como elemento esencial en el consentimiento del trabajador ${ }^{148}$. Fuera de ese ámbito, habrá que aplicar la regla general de no invalidación del contrato ${ }^{149}$.

\section{CONCLUSIONES}

La puntos que resumen las conclusiones de este trabajo son:

$1^{\circ}$ Desde una perspectiva laboral, simulación ilícita, fraude o abuso de Derecho, aun cuando son figuras rigurosamente distintas, han sido tratadas de manera uniforme, tanto por la doctrina como la jurisprudencia, en el entendido de que mediante ellas se busca eludir normas imperativas.

$2^{\circ}$ Para remediar estas situaciones, que en la práctica afectan a la identificación del empleador verdadero o responsable, se han estructurado diversas alternativas de solución entre las cuales destacan la protección de la apariencia jurídica. Esto ha traído como consecuencia que en el Derecho del Trabajo la teoría de la apariencia haya sido utilizada como un instrumento idóneo para evitar la falsedad, el fraude y el abuso de Derecho.

error, si en vez de ser ese constructor don N.N. lo es otra persona de quien el citado es solamente un gerente o representante legal".

${ }^{147}$ Martínez Giron, Jesús, cit. (n. 73), p. 76.

${ }^{148}$ Blasco Pellicer, Ángel, La individualización de las relaciones laborales (Madrid, Departamento de Publicaciones Consejo Económico y Social, 1995), p. 73; y PLA RodríGuez, Curso, cit. (n. 143), II,1, p. 121.

${ }^{149}$ Más dudosa sería la cuestión si el trabajador ha optado por contratar en atención a la capacidad económica del empleador. Lo cierto es que las condicionantes patrimoniales de un sujeto son esencialmente transitorias, y no parece razonable pretender anular el contrato debido a que dicha capacidad no existía al momento de celebrarse el acto jurídico-laboral. No obstante, operará dicha fundamentación del error cuando ella sea razonable y efectivamente exigida. Véase: Alonso Olea, Manuel - Casas BAAMONDE, María Emilia, cit. (n. 30), p. 192, teniéndolo presente como una cualidad esencial, y siempre que exista un evidente nexo entre ${ }_{\text {el }}$ error y la finalidad pretendida con el contrato [cfr. Sempere Navarro, Antonio, cit. (n. 140), p. 697]. Asimismo, carecerá de relevancia jurídica en cuanto vicio del consentimiento, la posible situación de apremio económico que obliga al trabajador a contratar. Si ese fue el motivo esencial para prestar el consentimiento, el contrato de trabajo no será anulable, independientemente de la capacidad patrimonial del empleador. Véanse: Montoya Melgar, Alfredo, Derecho, cit. (n. 31(, p. 303; y también, Sala Franco, Tomás - López Mora, Federico, cit. (n. 13), p. 4. 
$3^{\circ}$ El uso de la doctrina de la apariencia ha servido para que, en determinados casos, se respete la apariencia creada; y en otros, se opte por un criterio antiformalista que permita demostrar la eventual responsabilidad del empleador oculto. En cada una de estas alternativas, lo que ha prevalecido es el resultado más ventajoso para la parte afectada que es el trabajador.

$4^{\circ}$ Los problemas de simulación y apariencia han sido resueltos en el Derecho del Trabajo llevando a cabo una cuidadosa y fructífera elaboración jurisprudencial, la cual se ha construido de manera esencialmente indiciaria, protegiendo al trabajador frente a situaciones ilegítimas de apariencia empresarial. Más allá de la posibilidad de que en determinados casos haya prevalecido una visión patológica de la actuación empleadora, no se puede negar que en esta elaboración jurisprudencial destaca una innegable opción valorativa en la cual se privilegia una idea general de justicia frente a situaciones no específicamente resueltas por el legislador.

\section{BIBLIOGRAFÍA}

albaladejo, Manuel, Derecho Civil (11 $1^{a}$ edición, Barcelona, José María Bosch, 1991), $\mathrm{I}, 2$.

ALbiol montecinos, Ignacio, Aspectos laborales de la transmisión de empresa (Madrid, Servicio de Publicaciones Ministerio de Trabajo y Seguridad Social, 1984).

ALONso garcía, Manuel, Curso de Derecho del trabajo (10ª edición, Barcelona, Ariel, 1987).

alonso olea, Manuel - CaSas baamonde, María Emilia, Derecho del trabajo (13 edición, Madrid, Servicio de Publicaciones, Facultad de Derecho Universidad Complutense, 1993).

Amorós Guardiola, Manuel, El acreedor aparente, en AA. VV., Estudios jurídicos en homenaje al profesor Federico De Castro (Madrid, Tecnos, 1976), I.

Ángel Yagüez, Ricardo de, Apariencia jurídica, posesión y publicidad inmobiliaria registral (reimpresión, Bilbao, Publicaciones de la Universidad de Deusto, 1982).

Batlle Vázquez, Manuel, Artículo $6^{\circ}$, en Albaladejo, Manuel (director), Comentarios al Código Civily Compilaciones Forales (Madrid, 1978), I.

Bayón Chacón, Gaspar - Pérez Botija, Eugenio, Manual de Derecho del trabajo (11 a edición, Madrid, Marcial Pons, 1977-1978), I.

Blasco Pellicer, Ángel, La individualización de las relaciones laborales (Madrid, Departamento de Publicaciones Consejo Económico y Social, 1995).

Borrajo Dacruz, Efrén, El abuso de derecho en el contrato de trabajo, en Revista de Derecho del Trabajo, 1 (1954) 1.

Broseta Pont, Manuel, Manual de Derecho mercantil (7a edición, Madrid, Tecnos 1987).

Canaño Rojo, Eduardo, Análisis critico sobre la aplicación de la doctrina de los actos propios en materia laboral, en Revista de Derecho de la Pontificia Universidad de Valparaiso, 32 (1 ${ }^{\mathrm{er}}$ semestre 2009). 
Cabanellas, Guillermo, Tratado de Derecho laboral (3ª edición, Buenos Aires, Heliasta, 1987), II,1.

CAPón Filas, Rodolfo, El abuso del Derecho en relación al contrato de trabajo, en AA. VV., Estudios de derecho individual de trabajo en homenaje al profesor Mario L. Deveali (Buenos Aires, Heliasta, 1979).

Carballo Mena, César Augusto, Comentarios sobre la simulación en el Derecho del trabajo venezolano (su incidencia sobre la libertad sindical), en HERNÁNDEZ ÁLVAREZ, Óscar (coordinador), La Reforma Laboral en América Latina (Venezuela, Tipografía Horizonte, 1995).

Casas BaAmonde, María Emilia, Irregularidad formal, fraude de ley y nulidad del despido disciplinario, en Relaciones Laborales, 24 (1994).

Castán Tobeñas, José, Derecho civil español, común y foral (reimpresión de la $14^{a}$ edición, Madrid, Instituto Editorial Reus, 1987), I,2 y 3.

De Los Mozos, José Luis, El principio de la buena fe (Barcelona, Bosch, 1965).

Díez Duarte, Raúl, La simulación de contrato en el Código Civil chileno (2a edición, Santiago, Fallos del Mes, 1982).

Díez-Picazo, Luis - Gullón, Antonio, Sistema de Derecho civil (6a edición, Madrid, Tecnos, 1992), II.

FAdel RAAD, Nabil, L'abus de la personnalité morale en Droit privé (Paris, Librairie Générale de Droit et de Jurisprudence, 1991).

Fernández Gianotti, Enrique, Fraude de derechos laborales, en Relaciones Laborales, 1 (1991).

Ferrara, Francisco, La simulación de los negocios jurídicos (reimpresión, traducción castellana de Rafael Atard y Juan A. De la Puente, Madrid, Editorial Revista de Derecho Privado, 1960).

Galiana Moreno, Jesús María, El fraude de ley en las relaciones de trabajo: un análisis jurisprudencial, en Montoya Melgar, Alfredo - Martin Valverde, Antonio RodrígueZ-SAÑudo GutiérRez, Fermín (coordinadores), Cuestiones actuales de Derecho del trabajo. Homenaje al profesor Manuel Alonso Olea (Madrid, Publicaciones Ministerio del Trabajo y Seguridad Social, 1990).

García Murcia, Joaquín, El trabajo en contratas y la cesión de mano de obra en el Estatuto de los Trabajadores, en Revista de Politica Social, 130 (1981).

García Piqueras, Manuel, La simulación en el contrato de trabajo, en Actualidad Laboral, 21 (1990).

García VAlverde, María, Los elementos esenciales del contrato de trabajo: visión jurisprudencial, en Documentación Laboral, 45 (1995) 1.

GARCÍA VIÑa, Jordi, El despido nulo por abuso de derecho y fraude de ley: análisis jurisprudencial, en Actualidad Laboral, 45 (1993).

GonZÁlez Rodríguez, Manuel, Bocetos jurídicos: la buena fe y la seguridad jurídica, en Anales de la Academia Matritense del Notariado, 3 (1946).

Gordillo, Antonio, Comentario a la STS de 3 de junio de 1991, en Cuadernos Civitas de Jurisprudencia Civil (abril-agosto de 1991).

GoRdillo, Antonio, La representación aparente. Una aplicación del principio general de protección de la apariencia jurídica (Sevilla, Publicaciones de la Universidad, 1978).

Herrero Nieto, Bernardino, La simulación y el fraude a la ley en el Derecho del trabajo (Barcelona, Bosch, 1958). 
Irureta Uriarte, Pedro, Vigencia del principio de la buena fe en el Derecho del trabajo chileno, en Ius et Praxis, 17 (2011) 2.

Iruzubieta Fernández, Rafael, El abuso del Derecho y el fraude de ley en el Derecho del trabajo (Madrid, Colex, 1989).

JimÉnEZ SÁnCHEZ, Guillermo J., Lecciones de Derecho mercantil (reimpresión, Madrid, Tecnos, 1993).

JoRDANO BAREA, Juan, La teoría del heredero aparente y la protección de los terceros, en AA. VV., Estudios jurídicos en homenaje al profesor Federico De Castro (Madrid, Tecnos, 1976), II.

LASARTE, Carlos, Sobre la integración del contrato: la buena fe en la contratación (en torno a la Sentencia del T. S. de 27 de enero de 1977), en Revista de Derecho Privado (enero de 1980).

Lizama Portal, Luis, Derecho del trabajo (Santiago, LexisNexis, 2003).

Lizama Portal, Luis - Ugarte Cataldo, José Luis, Subcontratación y suministro de trabajadores ( $2^{a}$ edición, Santiago, LexisNexis, 2007).

López López, Julio, La contratación temporal y el fraude de ley, en Relaciones Laborales, 2 (1990).

Lorenzetti, Ricardo Luis, El fraude en el Derecho laboral, en AA. VV., Fraudes (Santa Fe, Revista de Derecho Privado y Comunitario, 1993).

Luján AlCARAZ, José, La contratación privada de servicios y el contrato de trabajo (Madrid, Centro de Publicaciones Ministerio de Trabajo y Seguridad Social, 1994).

Martin Valverde, Antonio, Interposición y mediación en el contrato de trabajo, en Revista de Politica Social, 91 (1971).

Martínez Girón, Jesús, El empresario aparente (Madrid, Civitas, 1992).

Menéndez Menéndez, Aurelio, Auxiliares del empresario, en Revista de Derecho Mercantil, 27 (1959).

Menezes Cordeiro, António, Manual de Dereito do trabalho (reimpresión, Coimbra, Livraria Almedina, 1994).

Molero Manglano, Carlos, La supletoriedad del Derecho común en el Derecho del trabajo (Madrid, Instituto de Estudios Políticos, 1975).

Molina Navarrete, Cristóbal, Persona jurídica y disciplina de los grupos de sociedades (Zaragoza, Publicaciones del Real Colegio de España, Bolonia, 1995).

Monereo Pérez, José Luis, Las relaciones de trabajo en la transmisión de la empresa (Madrid, Servicio de Publicaciones Ministerio de Trabajo y Seguridad Social, 1987).

Montoya Melgar, Alfredo, Derecho del trabajo (29a edición, Madrid, Tecnos, 2008).

Montoya Melgar, Alfredo, La buena fe en el Derecho del trabajo (Madrid, Tecnos, 2001).

Navarro Fernández, José Antonio, El fraude de ley: su tratamiento jurisprudencial (Madrid, Montecorvo, 1988).

Núñez Lagos, R., Mandatario sin poder, en Revista de Derecho Privado, 30 (1946) 354.

OJeda Avilés, Antonio, La renuncia de derechos del trabajador (Madrid, Instituto de Estudios Políticos, 1971).

OJEDA AvilÉs, Antonio, Los despidos radicalmente nulos por fraude deley, en Relaciones Laborales, 24 (1987).

Palomeque López, Manuel Carlos - Álvarez de la Rosa, Manuel, Derecho del trabajo ( $3^{a}$ edición, Madrid, Centro de Estudios Ramón Areces, 1995). 
Palomeque López, Manuel Carlo, Validez del contrato, en Borrajo Dacruz, Efrén, Comentarios a las Leyes Laborales. El Estatuto de los Trabajadores (Editorial de Derecho Reunidas, Madrid, 1985), III.

Pla Rodríguez, Américo, Curso de Derecho laboral (segunda reimpresión, Montevideo, Ediciones Idea, 1990), I,1.

Pla Rodríguez, Américo, Los principios del Derecho del trabajo (2a edición, Buenos Aires, Depalma, 1990).

Prado Puga, Arturo, Distinción conceptual entre los poderes aparentes y los poderes tácitos: un ensayo de aplicación al factor o gerente, en BARROS BOURIE, Enrique (coordinación), Contratos (Santiago, Editorial Jurídica de Chile, 1991).

Rey Guanter, Salvador, Potestad sancionadora de la administración y jurisdicción penal en el orden social (Madrid, Centro de Publicaciones Ministerio de Trabajo y Seguridad Social, 1990).

RODRÍGuez RAmos, María José, La cesión ilegal de trabajadores tras la reforma de 1994 (Madrid, Tecnos, 1995).

Rodríguez-Piñero Royo, Miguel, Cesión de trabajadores y empresas de trabajo temporal (Madrid, Centro de Publicaciones Ministerio de Trabajo y Seguridad Social, 1992).

RodrígueZ-PIÑERo Royo, Miguel, La presunción de existencia del contrato de trabajo (Madrid, Civitas, 1985).

Rojas Miño, Irene, La externalización laboral y la cesión ilegal de trabajadores en el sistema jurídico chileno, en Ius et Praxis 16 (2010) 1.

Rojas Miño, Irene, Subcontratación laboral, suministro de trabajo y cesión ilegal de trabajadores. (Santiago, AbedeloPerrot/Thomson Reuters, 2011).

Sagardoy Bengoechea, Juan Antonio, Los principios de aplicación del Derecho del trabajo (2a edición, Madrid, ACARL, 1991).

Sala Franco, Tomás - López Mora, Federico, Contrato de trabajo, en Borrajo DACRUZ, Efrén, Comentarios a las Leyes Laborales. El Estatuto de los Trabajadores (Editorial de Derecho Reunidas, Madrid, 1985), I.

Sempere Navarro, Antonio Vicente, Los elementos esenciales del contrato de trabajo en la jurisprudencia, en Montoya Melgar, Alfredo - Martin Valverde, Antonio - Rodríguez-Sañudo Gutiérrez, Fermín (coordinadores), Cuestiones actuales de Derecho del trabajo. Homenaje al profesor Manuel Alonso Olea (Madrid, Publicaciones Ministerio del Trabajo y Seguridad Social, 1990).

Talón Martínez, Francisco T., La apariencia jurídica, en Revista Jurídica de Cataluña, 51 (1952) 69.

Ugarte Cataldo, José Luis, El nuevo Derecho del trabajo (Editorial Universitaria, Santiago 2004).

URía, Rodrigo, Derecho mercantil (18 edición, Madrid, Marcial Pons, 1991).

Vázeuez Vialard, Antonio, Tratado de Derecho del trabajo (Buenos Aires, Astrea, 1982), V.

WIEACKER, Franz, El principio general de la buena fe (Madrid, Civitas, 1977). 